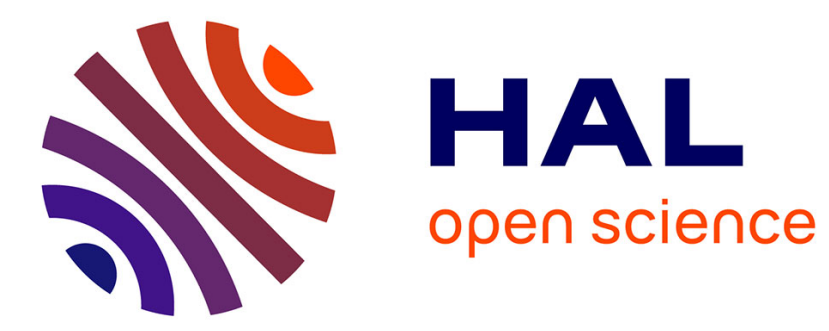

\title{
International Spillover Effects of Unconventional Monetary Policies of Major Central Banks
}

\author{
Tomoo Inoue, Tatsuyoshi Okimoto
}

\section{To cite this version:}

Tomoo Inoue, Tatsuyoshi Okimoto. International Spillover Effects of Unconventional Monetary Policies of Major Central Banks. 2020. hal-02938960v2

\section{HAL Id: hal-02938960 \\ https://hal.science/hal-02938960v2}

Preprint submitted on 24 Sep 2020

HAL is a multi-disciplinary open access archive for the deposit and dissemination of scientific research documents, whether they are published or not. The documents may come from teaching and research institutions in France or abroad, or from public or private research centers.
L'archive ouverte pluridisciplinaire HAL, est destinée au dépôt et à la diffusion de documents scientifiques de niveau recherche, publiés ou non, émanant des établissements d'enseignement et de recherche français ou étrangers, des laboratoires publics ou privés.

\section{(1)(1) $\$(0)$}

Distributed under a Creative Commons Attribution - NonCommercial - ShareAlikel 4.0 


\title{
FONDATION FRANCE-JAPON DE L'EHESS FFJ DISCUSSION PAPER \#20-05
}

\section{International Spillover Effects of Unconventional Monetary Policies of Major Central Banks}

Tomoo Inoue

(Seikei University)

\author{
Tatsuyoshi Okimoto \\ (Australian National University) \\ 2019 FFJ/Banque de France Fellow
}

September 2020 


\title{
International Spillover Effects of Unconventional Monetary Policies of Major Central Banks
}

\author{
Tomoo Inoue \& Tatsuyoshi Okimoto
}

\begin{abstract}
This study examines the effects of unconventional monetary policies (UMPs) by the major central banks, namely the Bank of England (BOE), Bank of Japan (BOJ), European Central Bank (ECB) and the Federal Reserve (Fed) on the international financial markets, taking global spillovers into account. To this end, we apply the Global Vector Autoregressive (GVAR) model to 35 countries and one region for the period from March 2009 to July 2019. Our results indicate that the effects vary across four asset classes and central banks. For example, the UMPs of the Fed and the BOJ have signicant impacts on the regional sovereign bond markets, while the ECB UMPs show relatively stronger and broader effects on global bond markets. The global equity markets were also considerably affected by UMPs of the Fed, ECB, and BOJ. Furthermore, we found some evidence of monetary policy interactions amongst the four major central banks. This resulted in the effects being less persistent on the global bond markets for the Fed and the ECB, but more persistent on equity and foreign exchange markets for the Fed and the BOJ.
\end{abstract}

\section{Keywords}

Unconventional Monetary policy, Financial linkage, International spillover, Global VAR JEL Classification: C32, E44, F41, F47, O50

\section{Acknowledgement}

We thank Etsuro Shioji and the participants of the FFJ/BdF workshop on monetary policy and macroeconomic issues, and the 2020 NFA annual meeting, for their helpful comments and discussions. This research was prepared in part while Okimoto was visiting the Fondation FranceJapon (FFJ) de l'EHESS and the Banque de France (BdF). He thanks the FFJ and the BdF for their support and hospitality during his stay. This research is partially funded by a grant-in-aid, from the Zengin Foundation for Studies in Economics and Finance (2019). The S\&P Dow Jones Indices LLC has kindly provided the sovereign and corporate bond price indices. 


\section{Contents}

1. Introduction

2. Models

2.1. GVAR model

2.2. Solving the GVAR model

3. Model Specification

3.1. Data

3.2. Model specification

3.2.1 Benchmark Model

3.2.2 Models of UK and Japan

3.2.3 Models of eurozone and member countries

3.2.4 Model of the US economy

4. Impulse Response Analysis with Sign Restrictions

4.1 Model 1: A model without monetary policy interactions

4.1.1 Effects of a UMP shock on the domestic financial markets

4.1.2 Effects of a UMP shock on the international financial markets

4.2 Model 2: A model with monetary policy interactions

4.2.1 Results of monetary policy interactions

4.2.2 UMP effects on domestic and international financial markets

5. Conclusion

Appendix

References

Tables \& Figures 


\title{
International Spillover Effects of Unconventional Monetary Policies of Major Central Banks*
}

\author{
Tomoo Inoue $e^{\dagger} \quad$ Tatsuyoshi Okimoto ${ }^{\ddagger}$
}

September 2020

\begin{abstract}
This study examines the effects of unconventional monetary policies (UMPs) by the major central banks, namely the Bank of England (BOE), Bank of Japan (BOJ), European Central Bank (ECB) and the Federal Reserve (Fed) on the international financial markets, taking global spillovers into account. To this end, we apply the Global Vector Autoregressive (GVAR) model to 35 countries and one region for the period from March 2009 to July 2019. Our results indicate that the effects vary across four asset classes and central banks. For example, the UMPs of the Fed and the BOJ have significant impacts on the regional sovereign bond markets, while the ECB UMPs show relatively stronger and broader effects on global bond markets. The global equity markets were also considerably affected by UMPs of the Fed, ECB, and BOJ. Furthermore, we found some evidence of monetary policy interactions amongst the four major central banks. This resulted in the effects being less persistent on the global bond markets for the Fed and the ECB, but more persistent on equity and foreign exchange markets for the Fed and the BOJ.
\end{abstract}

Keywords: Unconventional Monetary policy, Financial linkage, International spillover, Global VAR

JEL Classification Numbers: C32, E44, F41, F47, O50

\footnotetext{
${ }^{*}$ We thank Etsuro Shioji and the participants of the FFJ/BdF workshop on monetary policy and macroeconomic issues, and the 2020 NFA annual meeting, for their helpful comments and discussions. This research was prepared in part while Okimoto was visiting the Fondation France-Japon (FFJ) de l'EHESS and the Banque de France $(\mathrm{BdF})$. He thanks the FFJ and the BdF for their support and hospitality during his stay. This research is partially funded by a grant-in-aid, from the Zengin Foundation for Studies in Economics and Finance (2019). The S\&P Dow Jones Indices LLC has kindly provided the sovereign and corporate bond price indices.

${ }^{\dagger}$ Professor, Faculty of Economics, Seikei University. 3-3-1 Kichijoji-Kitamachi, Musashino, Tokyo 180-8633, Japan. Email: inoue@econ.seikei.ac.jp

${ }_{\ddagger}$ Associate Professor, Crawford School of Public Policy, Australian National University, FFJ/BdF fellow, FFJ de l'EHESS, and Visiting Fellow, Research Institute of Economy, Trade and Industry. 132 Lennox Crossing, ANU, Acton, ACT 2601, Australia. Email: tatsuyoshi.okimoto@anu.edu.au
} 


\section{Introduction}

After the global financial crisis (GFC) of 2008, many central banks, including the Federal Reserve (Fed), the European Central Bank (ECB), and the Bank of England (BOE) introduced so-called "unconventional monetary policies (UMPs)," such as large-scale asset purchases (LSAPs) and negative interest rates. Prior to this, the Bank of Japan (BOJ) pioneered UMPs by introducing Quantitative easing (QE) in March 2001 to combat its persistent deflation and stimulate its stagnant economy. Although it was abandoned in March 2006, the BOJ introduced its asset-purchasing program in October 2010 and a quantitative and qualitative easing (QQE) policy in April 2013.

There are a number of research papers assessing the impact of UMPs on domestic macroeconomy and financial markets, including for example, Curdia and Woodford (2011), Krishnamurthy and Vissing-Jorgensen (2011), D'Amico and King (2013), Gertler and Karadi (2013), Bauer and Rudebusch (2014), Haldane et al. (2016),Ihrig et al. (2018), Swanson (2018). There is also an increasing but still limited number of studies examining the spillover effects of UMPs of major central banks on the international macroeconomy and financial markets. The main purpose of this study is to provide new empirical evidence on this subject, focusing on the global spillover effects on international financial markets, specifically sovereign bonds, corporate bonds, stocks, and foreign exchange markets.

Over the last four decades, we have observed that the integration of global economic and financial markets has been promoted considerably, throughout, for example, an increase in world economic relations, competition and globalization, development of the global transportation system, reduction of trade barriers and financial market regulations, and an evolution in information technology. It is therefore not unreasonable to consider the global spillovers of monetary policy to international financial markets. For example, Bauer and Neely (2014) assesses the role of signaling and portfolio balance channels, on the international spillovers of the Fed's UMPs on global bond markets. Rey (2016) also discusses the possible transmission channels of US monetary policies to other countries. More specifically, the monetary policy of a center country could be transmitted to the periphery economies via the exchange rate, trade, credit, and risk-taking channels. In addition, Dedola et al. (2017) study international spillovers of US monetary policy shocks on macroeconomic and financial variables in 36 advanced and emerging economies. Sugimoto and Matsuki (2019) quantify international spillovers of major central banks on Asian stock markets. Kenourgios et al. (2019) investigate the effects of the ECB's UMPs on the cross-market movements across bond, stock, and currency forward markets. Although disentangling the transmission channels is not an easy task, in this study we empirically examine whether and how the transmission of major central banks' monetary 
policies to international financial markets are plausible and meaningful.

To assess the international spillover effects of the UMPs of major central banks on the international financial markets, we employ the Global Vector Autoregressive (GVAR) model, originally proposed in Pesaran et al. (2004). The GVAR model consists of a system of countryspecific VAR models containing domestic variables and weighted cross-section averages of foreign variables ${ }^{1}$ which are treated as weakly exogenous. Each VAR model is estimated conditional on the rest of the world, but is stacked and solved simultaneously as one large global VAR model to conduct the impulse response analysis. Consequently, the GVAR model can increase the model tractability and deal with the curse of dimensionality but still allows us to take the international transmission mechanism into account.

The GVAR model has been applied to examine the global spillover effects of monetary policies, including UMPs; for example, Georgiadis (2016) finds considerable output spillovers of the Fed's monetary policy to the rest of the world, which are larger than the domestic effects in the US for many economies. Similarly, Chen et al. (2016) show that the global spillovers of the US UMP effects on reductions in the US term and corporate bond spreads are sizable and vary across economies. Dekle and Hamada (2015) and Ganelli and Tawk (2019) document the positive and significant spillovers of the BOJ's monetary policy effects on Asian economies. Chen et al. (2017) analyze the spillover effects of the Fed and the ECB's UMPs on 24 economies and confirm that US UMPs generally have stronger domestic and cross-border impacts on output growth and inflation, than Euro area non-standard measures. Anaya et al. (2017) investigate international spillovers of the Fed's UMPs to emerging markets and identify the important role of capital flows. Burriel and Galesi (2018) quantify the heterogeneous effects of the ECB's UMPs across Euro area countries, suggesting that most Euro area members benefit from these measures but with substantial heterogeneity, the extent of which has been evolving over time and peaked with the sovereign debt crisis. Finally, Inoue and Okimoto (2019) demonstrate that the BOJ's UMPs have limited effects on international financial markets and that the spillovers of the Fed's UMPs are much larger.

Our study has several features that distinguishes it from the previous studies. Firstly, we analyze the effects of UMPs of the four largest central banks, namely the BOE, BOJ, ECB, and the Fed. Although there are many studies examining the effects of each central bank's UMPs, few of them assess the spillover effects of UMPs of these central banks simultaneously. We can conduct a more comprehensive analysis of the global spillover effects on international financial markets, by including these central banks. Secondly, related to the first feature, we consider the

\footnotetext{
${ }^{1}$ Individual units need not necessarily be countries, but could be regions, industries, municipalities or sectors of a given economy.
} 
possible coordination and/or interference among the four major central banks. Although the major central banks explicitly coordinate the monetary policy to overcome some crisis periods, for instance the GFC, they generally make monetary policy decisions independently. However, it is quite possible that one country's central bank's monetary policy affects other central banks' decisions. Therefore, we constructed our GVAR model to accommodate the possible feedback of each central bank's monetary policy. This feature is potentially very important when we consider the UMPs of four major central banks simultaneously. Thirdly, our analysis focuses on the recent UMP period from 2009 to 2019. Although, in this post-GFC period, the central banks of the major countries implemented UMPs, each of them used different measures to conduct the UMPs. For example, the Fed used QE or LSAPs as a major tool, while the ECB introduced a negative interest rate policy in addition to QE. The BOJ has also been extending QE by purchasing unconventional assets such as long-term government bonds, corporate bonds, and exchange-traded funds (ETFs) and accommodating negative interest rate and yield curve control. We also observed that the Fed started monetary policy normalization by raising policy rates in December 2015. Therefore, for our empirical analysis, we need a policy measure which can capture the various types of UMPs in a comprehensive manner. To address this issue, we employ the shadow short rate (SSR) of Krippner (2013) as a single monetary policy measure for the four major central banks. The SSR term structure models were developed to deal with the zero lower bound (ZLB) problem and capture the monetary policy stance under the ZLB environments. For example, Bullard (2012), Krippner (2013), and Wu and Xia (2016) argue that the SSR can be used as a single measure of both conventional and unconventional monetary policy stances. Similarly, Bauer and Rudebusch (2016) suggests that the SSR can capture monetary policy expectations. Following these studies, we use the SSR, as formulated by Krippner (2013) and his research on Europe, Japan, the UK, and the US, to measure their UMPs. More specifically, Kripnner's SSR is calculated using the arbitrage-free Nelson and Siegel (1987) models with two factors and a fixed 12.5 basis point lower bound. By using the SSR as a monetary policy indicator, we can compare monetary policy shocks on the same basis for the four major central banks. Combining these features results in our study being unique and meaningful. It provides new empirical findings on the global spillover effects of the UMPs of the major central banks on international financial markets.

The main findings of this study are summarized as follows: First, our results indicate that the UMPs of major central banks have significant expected easing effects on most domestic financial markets. Second, the Greek sovereign bond markets are boosted by the UMPs of all four central banks. In addition, the Fed and the BOJ's UMPs show significant impacts on the regional sovereign bond markets in general, while the ECB's UMPs seem to have relatively 
stronger and broader effects on global bond markets. In contrast, the BOE's UMPs have little effect on the global bond markets. Third, the Fed, ECB, and BOJ's UMPs raise the global equity markets considerably. Fourth, Fed's monetary easing has appreciated the exchange rates of almost all sample countries, while the ECB's monetary easing has depreciated the exchange rate of the eurozone and European currencies in general, but appreciated most of Asian and Pacific currencies. Alternatively, the BOE shows little impact on global foreign exchange markets, whereas the BOJ's monetary easing has significantly appreciated the exchange rates of Asian and Pacific currencies. Finally, we find some evidence of monetary policy coordination and/or interference among the four major central banks. Generally, these interactions do not affect the sign and magnitude of the effects of monetary easing policies by major central banks. However, the results also exhibit some differences in the persistence of the monetary policy spillover effects. The effects appear less persistent on the global bond markets for the Fed and ECB, but more persistent and stronger on the global equity and foreign exchange markets, for both the Fed and BOJ.

The remainder of this paper is organized as follows. Section 2 introduces the GVAR model. Section 3 describes the details of the model specifications. Section 4 summarizes the empirical results. Finally, Section 5 concludes the paper.

\section{Models}

\section{$2.1 \quad$ GVAR model}

In order to quantify the effects of UMPs on both domestic and global financial markets, we use a novel timeseries technique, the GVAR model, which was developed by, among others, Pesaran et al. (2004), Dees et al. (2007a), and Dees et al. (2007b).

The GVAR model is configured by a system of country-specific VARX* models. The $i$-th country-specific $\operatorname{VARX}^{*}\left(p_{i}, q_{i}\right)$ model $(i=1, \ldots, N)$ is written as: ${ }^{2}$

$$
\mathbf{x}_{i, t}=\mathbf{a}_{i 0}+\sum_{\ell=1}^{p_{i}} \boldsymbol{\Theta}_{i}^{(\ell)} \mathbf{x}_{i, t-\ell}+\sum_{\ell=0}^{q_{i}} \boldsymbol{\Lambda}_{i}^{(\ell)} \mathbf{x}_{i, t-\ell}^{*}+\mathbf{u}_{i t},
$$

where $\mathbf{x}_{i, t}$ represents the domestic variable vector; $\mathbf{x}_{i, t}^{*}$ denotes the foreign variable vector; $\mathbf{a}_{i 0}$ denotes the coefficients of a constant; $p_{i}$ represents the lag length of domestic variables; $q_{i}$ represents the lag length of foreign variables; $\boldsymbol{\Theta}_{i}^{(\ell)}$ and $\boldsymbol{\Lambda}_{i}^{(\ell)}$ represent the coefficient matrices with order $\ell$; and $\mathbf{u}_{i t}$ represents the idiosyncratic errors. At the time of estimation, we set the maximum lag lengths as $p_{i}=2$ and $q_{i}=1$. According to SIC, the optimal lag length of the

\footnotetext{
${ }^{2}$ Another commonly used specification in this literature is the global vector error-correction model with exogenous variables. In this paper, however, we do not consider the cointegrating relations among variables.
} 
variables turns out to be one, for all the economies. ${ }^{3}$

These countries" models are connected through the so-called "foreign" variables in each sub VARs. The foreign variables (sometimes called "star" variables) of country $i$ are constructed as:

$$
\mathbf{x}_{i t}^{*}=\sum_{j=1}^{N} w_{i j} \mathbf{x}_{j t}, \quad \text { with } w_{i i}=0
$$

where the term $w_{i j}$ represents the "closeness" between country $i$ and country $j$. Given that our model examines the shock transmissions between countries, mostly through financial markets, our $w_{i j}$ (for $i, j=1, \ldots, N$ ) represents the proximity between a pair of countries, in terms of financial activity, which we will discuss in more detail below.

A key idea is that the "foreign" variables are defined as a deterministic function of the other country's domestic variables, which increases the model tractability but still allows us to incorporate the international transmission mechanism into the model. At the time of estimating the parameters, the country-specific VARX* models are estimated one-by-one by assuming that the "foreign" variables are indeed "exogenous." For a dynamic analysis, for instance the impulse response analysis, the entire system is solved with the identity equations (2) that associate the "foreign" variables with the other country's "domestic" variables.

\subsection{Solving the GVAR model}

Throughout this paper, we fix the lag length as $p_{i}=1$ and $q_{i}=1$. Therefore, the specification of country-specific VARX* model, Eq (1), is simplified to $\operatorname{VARX}^{*}(1,1)$. The model for the $i$-th economy is now

$$
\mathbf{x}_{i t}=\mathbf{a}_{i 0}+\Theta_{i 1} \mathbf{x}_{i, t-1}+\Lambda_{i 0} \mathbf{x}_{i t}^{*}+\Lambda_{i 1} \mathbf{x}_{i, t-1}^{*}+\mathbf{u}_{i t}
$$

Next, a vector of variables $\mathbf{z}_{i t}$ which stacks the domestic and foreign variables, is defined as follows.

$$
\mathbf{z}_{i t}=\left(\begin{array}{c}
\mathbf{x}_{i t} \\
\mathbf{x}_{i t}^{*}
\end{array}\right)
$$

With this variable, $\mathrm{Eq}(3)$ is rewritten as

$$
\mathbf{A}_{i 0} \mathbf{z}_{i t}=\mathbf{a}_{i 0}+\mathbf{A}_{i 1} \mathbf{z}_{i, t-1}+\mathbf{u}_{i t}
$$

where the relevant coefficient matrices are

$$
\mathbf{A}_{i 0}=\left(\mathbf{I}_{k_{i}},-\boldsymbol{\Lambda}_{i 0}\right), \quad \mathbf{A}_{i 1}=\left(\Theta_{i 1}, \boldsymbol{\Lambda}_{i 1}\right)
$$

\footnotetext{
${ }^{3}$ Reflecting on the fact that the adjustment process of financial variables is short, in general, we conservatively select the maximum lag length of our variables to be two.
} 
Recall that $\mathbf{x}_{i t}^{*}$ is expressed as a function of $\mathbf{x}_{j t}$, commonly as a weighted average of counterparties' identical variables. Thus, generally, one can link $\mathbf{z}_{i t}$ and $\mathbf{x}_{j t}$ by using the link matrices $\mathbf{W}_{i}$ as:

$$
\mathbf{z}_{i t}=\mathbf{W}_{i} \mathbf{x}_{t}
$$

where

$$
\mathbf{x}_{t}=\left(\begin{array}{c}
\mathbf{x}_{1 t} \\
\vdots \\
\mathbf{x}_{N t}
\end{array}\right)
$$

There is one exception. For constructing the regional average variable $\tilde{\mathbf{x}}_{\mathrm{E}, t}$ for the eurozone, the elements of standard link matrix are further combined by using the relative economic size of each eurozone member country, which is measured by the PPP-GDP. More importantly however, $\tilde{\mathbf{x}}_{\mathrm{E}, t}$ is a function of a sample country's domestic variables. Thus, it is possible to construct a suitable $\mathbf{W}_{i}$ matrix. With Eq (5), the VARX* model of country $i$, Eq (4), is finally rewritten as

$$
\mathbf{A}_{i 0} \mathbf{W}_{i} \mathbf{x}_{t}=\mathbf{a}_{i 0}+\mathbf{A}_{i 1} \mathbf{W}_{i} \mathbf{x}_{t-1}+\mathbf{u}_{i t}
$$

Next, by stacking $N$ countries, the entire system is written as

$$
\mathbf{G}_{0} \mathbf{x}_{t}=\mathbf{a}_{0}+\mathbf{G}_{1} \mathbf{x}_{t-1}+\mathbf{u}_{t}
$$

where

$$
\mathbf{a}_{0}=\left(\begin{array}{c}
\mathbf{a}_{10} \\
\vdots \\
\mathbf{a}_{N 0}
\end{array}\right), \quad \mathbf{G}_{j}=\left(\begin{array}{c}
\mathbf{A}_{1 j} \mathbf{W}_{1} \\
\vdots \\
\mathbf{A}_{N j} \mathbf{W}_{N}
\end{array}\right), \quad \mathbf{u}_{t}=\left(\begin{array}{c}
\mathbf{u}_{1 t} \\
\vdots \\
\mathbf{u}_{N t}
\end{array}\right)
$$

for $j=0,1$

Finally, by multiplying $\mathbf{G}_{0}^{-1}$ from the left, Eq (7) becomes

$$
\begin{aligned}
\mathbf{x}_{t} & =\mathbf{G}_{0}^{-1} \mathbf{a}_{0}+\mathbf{G}_{0}^{-1} \mathbf{G}_{1} \mathbf{x}_{t-1}+\mathbf{G}_{0}^{-1} \mathbf{u}_{t} \\
& =\mathbf{b}_{0}+\mathbf{F}_{1} \mathbf{x}_{t-1}+\mathbf{G}_{0}^{-1} \mathbf{u}_{t}
\end{aligned}
$$

where $\mathbf{b}_{0}=\mathbf{G}_{0}^{-1} \mathbf{a}_{0}$, and $\mathbf{F}_{1}=\mathbf{G}_{0}^{-1} \mathbf{G}_{1}$.

\section{Model specification}

\subsection{Data}

In this study, we estimate a GVAR model (1), consisting of $N=36$ region/country/economyspecific VARX* models at a monthly frequency. For a complete set of samples of these regions/countries/economies (and their mnemonic), see Table 1. 
Data is collected from various sources, including the International Monetary Fund, the Bank of International Settlement, and the CEIC. The sovereign and corporate bond price indices, denominated in the local currency units, are obtained from the S\&P Dow Jones Fixed Income Index. Our sample covers the period March 2009 to July 2019, or 125 months. We chose this sample period to focus on the analysis of UMP effects of major central banks. For the details of data construction, see Appendix.

\subsection{Model specification}

The eurozone and 35 sample countries are classified into five categories, depending on our research interests, the relative influence in the global financial markets, as well as the availability of a dataset. Therefore, four different specifications are presented in the following subsections.

Our main research interest is the quantification of the UMP effects of the major central banks on their domestic and global financial markets, through their networks. More specifically, we evaluate the UMPs conducted by the BOE in the UK, the BOJ in Japan, the ECB in the eurozone, and the Fed in the US. Therefore, models of these four parties explicitly include the monetary policy variable.

In addition, they are divided into two groups, depending on the size of the economy: the US and the eurozone are treated as large-open economies; and the UK and Japan are smallopen economies. In terms of specification, although the financial markets of the small-open economies are contemporaneously affected by the global factors, which is represented by $\mathbf{x}^{*}$, this is not the case for the large-open economies. Thus, although $\mathbf{x}^{*}$ are weakly exogenous variables for the UK and Japan, they are not for the US and the eurozone.

The next important point of specification is the treatment of the eurozone member countries. Neither the monetary policy nor the exchange rate is determined by a single member country. Their monetary policies are conducted by the ECB, thus its decisions are treated as exogenous for each member country. Moreover, since they use a common currency, each member country has no discretionary power to change its relative value alone. In this regard, the exchange rate should also be treated as exogenous.

One final issue is the availability of data. Both the equity price index and the sovereign bond price index are available for all the sample countries. The bilateral exchange rate (with respect to one US Dollar) is also available for all. However, since they take the same values among the eurozone member countries, they are excluded from the dataset of each member country, and included in the EMU unit. The monetary policy variables are included only for the US, the eurozone, the UK and Japan. Lastly, the corporate bond price index is missing for three of the Latin American countries Chile, Colombia, and Mexico(CHL, COL, and MEX), 
and South Africa (ZAF). For the eurozone, only the aggregated corporate bond price index is released. Therefore, it is included in the EMU unit model.

\subsubsection{Benchmark Model}

A standard country-specific VARX* model in the Global VAR literature is written as follows.

$$
\mathbf{x}_{i t}=\mathbf{a}_{i 0}+\underbrace{\Theta_{i 1} \mathbf{x}_{i, t-1}}_{\text {domestic }}+\underbrace{\Lambda_{i 0} \mathbf{x}_{i t}^{*}+\Lambda_{i 1} \mathbf{x}_{i, t-1}^{*}}_{\text {foreign }}+\mathbf{u}_{i t}
$$

where $\mathbf{x}_{i t}$ is a set of endogenous variables for country $i$, and $\mathbf{x}_{i t}^{*}$ is a set of exogenous foreign variables for country $i$. For most of the sample countries, the endogenous variable vector includes its sovereign bond price index $s_{i t}$ (the mnemonic used in the figures of impulse response functions below, is $\mathrm{sb}$ ), the corporate bond price index $c_{i t}(\mathrm{cb})$, the equity price index $q_{i t}$ (eq), and the exchange rate $e_{i t}(\mathrm{fx})$. All variables are log-transformed. Notice that $s_{i t}$, $c_{i t}$, and $q_{i t}$ are evaluated in local currency units.

$$
\mathbf{x}_{i t}=\left(\begin{array}{c}
s_{i t} \\
\left(c_{i t}\right) \\
q_{i t} \\
e_{i t}
\end{array}\right), \quad \mathbf{x}_{i t}^{*}=\left(\begin{array}{c}
s_{i t}^{*} \\
c_{i t}^{*} \\
q_{i t}^{*}
\end{array}\right)
$$

In the above equation, the corporate bond price index $c_{i t}$ is in brackets since it is included when it is available. The exchange rate $e$ is the bilateral rate with respect to the US Dollar, and is defined as:

$$
e_{i t}=\frac{\text { USA Dollar }}{\text { Country } i \text { 's Domestic Currency }}
$$

As for the exogenous variable, three financial variables, $s^{*}, c^{*}$, and $q^{*}$, are included.

Foreign variables for country $i, \mathbf{x}_{i t}^{*}$, are constructed by weighting the same variables in the foreign dataset. The foreign variables are included in the model in order to approximate the unobservable foreign effects. Thus, it is desirable to reflect some magnitude of exposure.

For this weight, data such as trade shares or portfolio shares are typically used. The idea is that the tighter the connection between countries, the more the one country will be exposed to the shock of the other country. In this study, we use the trade shares as a measure of proximity. ${ }^{4}$

It is well-known that over the last two decades, the global financial market has been highly integrated. The use of a single country VAR model under such circumstances presents the risk of omitting some important influences outside of its country. By including the foreign variables, the GVAR model can capture this global transmission effect, if it exists.

\footnotetext{
${ }^{4}$ We also considered using the CPIS (Coordinated Portfolio Investment Survey) and the CDIS (Coordinated direct Investment Survey), both from IMF, for this purpose. However, some of data are not available for whole sample periods and all target countries, thus we used the trade data to measure proximity.
} 


\subsubsection{Models of UK and Japan}

For the UK and Japan, a similar model is used, but with a different set of data, as follows:

$$
\mathbf{x}_{i t}=\mathbf{a}_{i 0}+\underbrace{\Theta_{i 1} \mathbf{x}_{i, t-1}}_{\text {domestic }}+\underbrace{\Lambda_{i 0} \mathbf{x}_{i t}^{*}+\Lambda_{i 1} \mathbf{x}_{i, t-1}^{*}}_{\text {foreign }}+\mathbf{u}_{i t}
$$

where

$$
\mathbf{x}_{i t}=\left(\begin{array}{c}
m_{i t} \\
s_{i t} \\
c_{i t} \\
q_{i t} \\
e_{i t}
\end{array}\right), \quad \mathbf{x}_{i t}^{*}=\left(\begin{array}{c}
\left(m_{i t}^{*}\right) \\
s_{i t}^{*} \\
c_{i t}^{*} \\
q_{i t}^{*}
\end{array}\right)
$$

with $i$ is either the UK or Japan. During the sample period, various unconventional monetary policies are conducted, which compels us to use either a short interest rate or a monetary base alone, as a monetary policy variable. Thus, as our best alternative, we use the shadow short rate, $m_{i t}$ (the mnemonic is $\mathrm{mp}$ ), which is based on Krippner (2013) and his research.

The instantaneous value of foreign variables $\mathbf{x}_{i t}^{*}$ is included in the right-hand side, based on the assumption that UK and Japan are small open economies and $\mathbf{x}_{i t}^{*}$ is weakly exogenous. In the following, we have estimated two scenarios: One with no monetary policy interactions, by excluding $m_{i t}^{*}$ from $\mathbf{x}_{i t}^{*}$ (Model 1); and the other with monetary policy interactions, by including $m_{i t}^{*}$ from $\mathbf{x}_{i t}^{*}$ (Model 2). See Table 2 for details. The variable $m_{i t}^{*}$ is put in parentheses, since its inclusion depends on this specification.

\subsubsection{Models of eurozone and member countries}

Each of the eurozone member countries are modeled as follows:

$$
\mathbf{x}_{i t}=\mathbf{a}_{i 0}+\boldsymbol{\Theta}_{i 1} \mathbf{x}_{i, t-1}+\Lambda_{i 0} \mathbf{x}_{i t}^{*}+\Lambda_{i 1} \mathbf{x}_{i, t-1}^{*}+\underbrace{\boldsymbol{\Psi}_{i 0} \mathbf{x}_{\mathrm{E}, t}+\mathbf{\Psi}_{i 1} \mathbf{x}_{\mathrm{E}, t-1}}_{\text {eurozone related variables }}+\mathbf{u}_{i t}
$$

where

$$
\mathbf{x}_{i t}=\left(\begin{array}{c}
s_{i t} \\
q_{i t}
\end{array}\right), \quad \mathbf{x}_{i t}^{*}=\left(\begin{array}{c}
s_{i t}^{*} \\
c_{i t}^{*} \\
q_{i t}^{*}
\end{array}\right), \quad \mathbf{x}_{\mathrm{E}, t}=\left(\begin{array}{c}
m_{\mathrm{E}, t} \\
c_{\mathrm{E}, t} \\
e_{\mathrm{E}, t}
\end{array}\right)
$$

The model of a eurozone member country is different from the previous models in two ways. Firstly, it only has two endogenous variables. For all the eurozone countries, two variables, namely the sovereign bond price index $s_{i}$ and the equity price index $q_{i}$, are included in the endogenous variable vector $\mathbf{x}_{i t}$. Secondly, the exogenous variables are comprised of two categories: One is eurozone related variables $\mathbf{x}_{\mathrm{E}, t}$; and the other category is standard foreign variables $\mathbf{x}_{i, t}^{*}$. 
Unlike other sample economies, the eurozone member countries do not have country-specific exchange rates. Therefore, $e_{\mathrm{E}, t}$ is determined in the regional model, and hence treated as exogenous to each member country. Moreover, monetary policy is determined by the ECB, thus the monetary policy variable $m_{\mathrm{E}, t}$ is also treated as exogenous to each member country. In addition, due to the lack of a country-specific corporate bond price index $c$, its dynamics are modeled in the regional model.

Then the dynamics of $\mathbf{x}_{\mathrm{E}, t}$ are modeled as follows:

$$
\mathbf{x}_{\mathrm{E}, t}=\mathbf{a}_{\mathrm{E}, 0}+\boldsymbol{\Theta}_{\mathrm{E}, 1} \mathbf{x}_{\mathrm{E}, t-1}+\boldsymbol{\Lambda}_{\mathrm{E}, 0} m_{\mathrm{E}, t}^{*}+\boldsymbol{\Lambda}_{\mathrm{E}, 1} \tilde{\mathbf{x}}_{\mathrm{E}, t-1}+\mathbf{u}_{\mathrm{E}, t}
$$

where

$$
\mathbf{x}_{\mathrm{E}, t}=\left(\begin{array}{c}
m_{\mathrm{E}, t} \\
c_{\mathrm{E}, t} \\
e_{\mathrm{E}, t}
\end{array}\right), \quad \tilde{\mathbf{x}}_{t}=\left(\begin{array}{c}
\left(m_{\mathrm{E}, t}^{*}\right) \\
\tilde{s}_{\mathrm{E}, t} \\
\tilde{q}_{\mathrm{E}, t}
\end{array}\right)
$$

This is the model for a eurozone unit. This reflects the aim of the monetary policy, as it includes the eurozone regional aggregates $\tilde{\mathbf{x}}_{t}$ as exogenous variables. Eurozone regional aggregates $\tilde{\mathbf{x}}_{t}$ include the averages of the sovereign bond price index and the equity price index. Both are constructed by aggregating the eurozone member country-specific indexes. For aggregation, we use the sample average of PPP-GDP of each member country, which is measured by the 2009-2018 average of the PPP evaluated GDP of these countries.

$$
\tilde{s}_{\mathrm{E}, t}=\sum_{j \in \mathrm{E}} w_{j}^{\mathrm{GDP}} s_{j t}, \quad w_{j}^{\mathrm{GDP}}=\frac{\mathrm{PPP}-\mathrm{GDP}_{j}}{\text { Region total PPP-GDP }},
$$

In order to model the ECB's policy reaction to other central banks' policies, the weighted average of the foreign shadow short rate $m_{\mathrm{E}}^{*}$ is also included for Model 2. We also add a term $\boldsymbol{\Lambda}_{\mathrm{E}, 0} m_{\mathrm{E}, t}^{*}$, expecting that it captures an instantaneous policy response, if any, while minimizing the problem of endogeneity. Note that $\boldsymbol{\Lambda}_{\mathrm{E}, 0}$ is a $3 \times 1$ coefficient vector.

\subsubsection{Model of the US economy}

Lastly, the model for the US is presented. The US's exchange rate is the weighted averages of its counter-parties' exchange rate $e_{i t}$. Therefore, it is included as an exogenous variable.

$$
\mathbf{x}_{\mathrm{U}, t}=\mathbf{a}_{\mathrm{U} 0}+\Theta_{i 1} \mathbf{x}_{\mathrm{U}, t-1}+\Lambda_{\mathrm{U} 0} m_{\mathrm{U}, t}^{*}+\Lambda_{\mathrm{U} 1} \mathbf{x}_{\mathrm{U}, t-1}^{*}+\mathbf{u}_{\mathrm{U} t}
$$

where

$$
\mathbf{x}_{i t}=\left(\begin{array}{c}
m_{\mathrm{U}, t} \\
s_{\mathrm{U}, t} \\
c_{\mathrm{U}, t} \\
q_{\mathrm{U}, t}
\end{array}\right), \quad \mathbf{x}_{i t}^{*}=\left(\begin{array}{c}
\left(m_{\mathrm{U}, t}^{*}\right) \\
e_{\mathrm{U}, t}^{*}
\end{array}\right)
$$


Similar to the treatment of the ECB model, both an instantaneous and one lag of $m_{\mathrm{U}, t}^{*}$ are added in order to examine the policy interactions between the four central banks, only for Model 2.

\section{Impulse Response Analysis with Sign Restrictions}

To quantify the effects of the UMPs by major central banks, we assess the impulse responses to a monetary easing shock of each central bank. One important issue to do so based on the VAR analysis is how to identify monetary policy shocks. One classical approach to do so is based on the block recursive assumptions by Christiano et al. (1999). In this approach, the central banks are assumed to decide their monetary policy based on the current economic conditions only but not the financial market conditions. This assumptions used to be reasonable, since the main interest of the monetary policy is the domestic economy. However, the domestic financial market conditions have become one of the most important factors of the domestic economy as the financial markets develop. Therefore, the block recursive approach may not be preferable, particularly because we focus on the data after the GFC in 2008. To overcome this problem, we identify the monetary policy shocks by imposing sign restrictions on the short-run impulse responses of the sovereign bond index and the equity price index, generated from the GVAR. More specifically, we assume that a monetary easing shock decreases the SSR and increases the domestic sovereign bond and equity prices. The sign restriction on the SSR is imposed upon impact, while those on asset prices are imposed upon impact and 2 months thereafter. Though both sovereign bond and equity price indices are available for each member country in the eurozone, the restrictions are imposed on the PPP-GDP weighted $\tilde{s}$ and $\tilde{q}$.

In the next subsections, we investigate how an unexpected monetary easing shock, defined by a $0.25 \%$ drop of the SSR, is transmitted to both domestic, as well as global financial markets.

\subsection{Model 1: A model without monetary policy interactions}

In this subsection, we address the issue of how four central banks' UMP shocks influence their domestic, as well as global financial markets, without taking monetary policy interactions among them into account (Model 1). To answer these questions, we conduct an IR analysis with sign restrictions. The IR graphs in the following subsections show the response paths of endogenous variables to a monetary easing shock defined by a $0.25 \%$ unpredictable drop in the SSR, to facilitate the comparison of policy effects across the Fed, ECB, BOE and BOJ. 


\subsubsection{Effects of a UMP shock on the domestic financial markets}

Figure 1 shows the impacts of a monetary easing shock of each central bank on its domestic financial markets, using an IR function. Each row corresponds to the responses of each country's SSR, sovereign and corporate bond prices, equity prices, and exchange rates to the monetary policy easing by the Fed, ECB, BOE, and BOJ, respectively.

As can be seen from the second column of the figure, the sovereign bond prices have risen in all four economies. The (median) response, immediately after the shock, is approximately $0.5 \%$ in the US and Japan, and nearly $1 \%$ in the eurozone and the UK. The persistence of the effects varies across the central banks. More specifically, the UK's response becomes insignificant after three months, but the responses in the US are significant even after one year.

The immediate response in the corporate bond market in the US is significant at about 1\%, and the effects remain for more than one year. Regarding the response of eurozone and the UK, the initial impact is approximately $0.6 \%$ but the effects have disappeared after 4 to 9 months. For Japan, the responses are essentially zero, over the entire period.

As for the equity market, the responses upon impact are positive and significant for all countries. More precisely, Japan has the largest response (4.4\%), followed by the US (2.1\%), the UK (1.5\%), and the eurozone (1.2\%). The high response in the Japanese stock market may reflect the aggressive purchase of ETFs by the BOJ, after the introduction of QQE in 2013. In regards to the persistence of the effects, the responses of the US and the eurozone are significant, even after one year, whereas those of the UK and Japan become insignificant within two quarters.

Finally, in the foreign exchange market, an unexpected monetary easing shock uniformly depreciates the relative value of the home currency. From the perspective of magnitude, Japan responds the most, with a little over $2 \%$ depreciation of the yen upon impact. However, its statistical significance disappears instantaneously. Though the size of depreciation is smaller $(1.6 \%)$, the effect on the euro is significant and lasts, even after one year. Also, the US dollar significantly depreciates by $0.6 \%$ upon impact, but the effect disappears after 5 months. Though the median response shows the currency depreciation as (0.9\%) in the UK, it is not significant over all periods.

In general, our results indicate that the UMPs of major central banks have expected easing effects on almost all domestic financial markets. The effects of the UMPs of the Fed are significant and persistent for all markets, while those of the ECB are significant for all markets, but not persistent for bond markets. The effects of the UMPs of the BOE are significant and temporal for bond and equity markets. Finally, those of the BOJ are significant and temporal only for the sovereign bond and equity markets. 


\subsubsection{Effects of a UMP shock on the international financial markets}

Figure 2 displays the responses of the sovereign bond prices to the each central bank's monetary easing shock, defined by the $0.25 \%$ decrease in the SSR, after one month and three months, respectively. Each row corresponds to the responses of each country's market to the monetary policy easing by the Fed, ECB, BOE, and BOJ. Similarly, the responses of the corporate bond prices, stock prices, and foreign exchange rates are plotted in Figures 3 to 5.

In the sovereign bond market, the noticeable positive and mostly significant responses of Greece, which experienced a financial crisis, are commonly observed, as shown in Table 3. Therefore, in order to display the responses of other sample countries, Greece has been omitted from Figure 2. As can be seen from Figure 2, the Fed's monetary easing shock has had price increasing effects on North and South American countries, such as Canada, Colombia and Mexico; and Asian countries, such as Indonesia and the Philippines. The ECB's monetary easing shock has significant and strong impacts on the global sovereign bond market, in general. This could be because the ECB applied relatively aggressive monetary policy measures, focusing on the European sovereign bond market to solve the European debt crisis. Consequently, the ECB's monetary easing policies have had significant effects on the European countries, as well as globally. In contrast, the BOE policy shock has little effect on overseas sovereign bond markets. Although some of the responses are significant, the magnitude is relatively small compared to other central banks. Finally, for the BOJ, significant positive impacts are observed mostly in Asian countries, for example Indonesia, the Philippines, and Thailand, although the effect lasts only for a short period.

Next, the reactions of the corporate bond markets are examined (See Figure 3). The Fed's monetary easing has raised the corporate bond prices significantly in Canada and Asian countries such as Indonesia, Malaysia, Singapore, and Thailand. These effects tend to remain in place after three months. The ECB's monetary easing has had significantly positive effects on the corporate bond markets all over the world and the effects remain significant for most of the countries, even after three months. On the contrary, the BOE policy shock has had little impact on global corporate bond markets. Finally, the BOJ's monetary easing has relatively strong and persistent effects on Asian corporate bond markets.

With respect to the equity market, all central banks' monetary easing policies have increased the stock prices globally, after one month (See Figure 4). In the case of the Fed and the ECB, the effects are relatively persistent and still significant after three months, for more than half of the countries. In contrast, the BOE's monetary easing has become ineffective after three months for most of the countries. Finally, the effects of the BOJ's monetary easing are significant after three months, mostly for Asian and Pacific countries. 
In the foreign exchange market, the Fed monetary easing has increased the bilateral exchange rates (against the US dollar) of almost all sample countries (See Figure 5). Exceptions are some of the European countries and Japan. On the other hand, the ECB's monetary easing has depreciated the exchange rate of the eurozone and European countries, in general, but appreciated the exchange rates of most Asian and Pacific countries. Finally, the BOE's monetary easing shows little impact on global foreign exchange markets, whereas the BOJ's monetary easing has significantly appreciated the exchange rates of Asian and Pacific countries. Since the bilateral currencies with respect to the US Dollar are used, panels (b), (c), and (d) of Figure 5 should be interpreted with caution. For instance, in panel (b), in the case of the Swedish Krona, it moves more closely with the euro and thus it would depreciate against the US Dollars. A similar situation is inferred for the Danish Krone and the Norwegian Krone, though the Swiss Franc seems to be rather independent from Euro's currency market.

In summary, our results indicate that the Fed's monetary easing has had significant impacts on the regional and Asian bond markets and global equity and foreign exchange markets. The ECB's policies seem to have stronger and broader effects on the global bond markets compared to other central banks, but weaker and less persistent effects on the global equity markets in comparison to the Fed. Our results suggest that the BOE's policy shock has little effect on global financial markets. Finally, the BOJ shows significant and persistent impacts mainly on Asian financial markets.

\subsection{Model 2: A model with monetary policy interactions}

In Model 2, the monetary policy variable $m^{*}$ is included in the models of the US, the eurozone, the UK and Japan. With this specification, we incorporate possible policy interactions among the Fed, ECB, BOE and BOJ. Although the major central banks explicitly coordinate their monetary policies to overcome some crisis periods, for instance the GFC, they generally make monetary policy decisions independently. However, it is quite possible that one country's central bank's monetary policy affects other central banks' decisions. By comparing the Models 1 and 2, we can examine the importance of accommodating the possible interference among the four major central banks.

\subsubsection{Results of monetary policy interactions}

The results of monetary policy interactions are summarized in Figure 6. The first row shows each central bank's policy responses to the Fed's monetary easing. As can be seen, the results indicate that the SSR of the eurozone and the UK respond significantly positively to the unexpected decrease in the US SSR. Note that this does not necessarily mean that their 
monetary policy tends to move in the opposite direction. Rather, this result suggests that the degree of monetary easing by the ECB and the BOE would be smaller than expected, when the Fed eases the monetary policy more than expected. In other words, the Fed's unexpected monetary easing should have some expansionary impacts on countries worldwide, including European countries, as confirmed above, and this allows the ECB and BOE to reduce the degree of monetary easing. In contrast, the SSR of Japan does not have a strong response to the shock in the SSR of the US, meaning that the BOJ's monetary policy is negligibly affected by the Fed's monetary policy. This is reasonable, given the BOJ's aggressive and unique monetary easing policies, aimed at overcoming long lasting deflation in the 2010s, particularly after the introduction of QQE.

The monetary policy responses of each central bank, to the ECB's monetary easing are shown in the second row of Figure 6. The results indicate that the SSRs of the US and UK significantly decrease when the SSR of the eurozone drops unexpectedly. This implies that the Fed and the BOE tend to conduct more aggressive monetary easing, following the ECB's unexpected monetary easing. The results also indicate that the magnitude of the decrease is much larger for the BOE. One possible explanation of the BOE's reaction is that the UK and eurozone have a close economic connection, as well as competition. Therefore, the BOE needs to adopt a similar degree of monetary policies as those of the ECB, to prevent the UK economy from losing its competitiveness. On the contrary, the SSR of Japan responds significantly positively, suggesting that the magnitude of monetary easing by the BOJ would be smaller than expected when the ECB conducts more aggressive monetary easing than expected.

As can be seen from the third row of Figure 6, the BOE's monetary policy shock does not affect the SSRs of other countries, meaning that no other central banks show strong responses to the BOE's UMP changes. On the contrary, the last row indicates that the BOJ's monetary policy shock tends to increase the SSRs of other countries. This suggests that when the BOJ conducts more aggressive monetary easing than expected, the magnitude of monetary easing by other major central banks would be smaller than expected. Therefore, the aggressive monetary policies by the BOJ, after the introduction of QQE, tends to help other central banks choose less aggressive monetary policies.

In summary, our analysis demonstrates some evidence of monetary policy coordination and/or interference among the four major central banks. For many cases, one central bank's monetary easing helps another central bank conduct less aggressive monetary easing, saving some room to further execute such policies in the future. One notable exception is the BOE's reaction to the ECB's monetary easing, showing its tendency to conduct similar monetary easing to that of the ECB. 


\subsubsection{UMP effects on domestic and international financial markets}

Next, we document the UMP effects on domestic and international financial markets. Generally, the results are close to those of the previous subsection. Therefore, we mainly summarize the difference in results between Models 1 and 2.

Figure 7 shows the responses of the domestic financial markets to an unexpected $0.25 \%$ drop of its own SSR, based on Model 2. As can be seen, the sign and magnitude of the responses are mostly the same as Model 1, but the policy effects become less persistent for the Fed. Another noticeable difference is the BOJ's policy effects on the Japanese equity and currency markets. In Model 1, the effects on equity markets disappear within five months, while those of model 2 remain significant up to seven months. Also, although the BOJ's monetary easing does not have any significantly persistent impacts on the Japanese foreign exchange rate in Model 1, it marginally depreciates the Japanese yen for two months after the impact in Model 2.

The results for the sovereign bond market reported in Figure 8 show very similar effects to those of Model $1 .^{5}$ Specifically, the results suggest that the monetary easing by the Fed tends to increase the sovereign bond prices, mainly for the regional countries and Asian countries, while the ECB has stronger and more global effects on the international sovereign bond market. In addition, the BOJ's easing significantly and positively affects the sovereign bond prices for Asian countries. However, the results also indicate that the effects for Model 2 are slightly less persistent, compared to Model 1. Moreover, a similar tendency can be observed in the results for the corporate bond prices shown in Figure 9.

As evident from Figure 10, the sign and size of the effects of monetary easing by major central banks on the international equity markets are quite similar with those of Figure 4 based on Model 1. This result is consistent with that of bond markets, but some differences can be found in the persistence of the effects. If Figures 4 and 10 are compared, the results of Model 2 suggest that the effects are more persistent than those of Model 1, for the Fed and the BOJ. Monetary easing policies for these two central banks increase the stock prices for almost all countries after one month and these effects remain in place for most countries, even after three months.

Lastly, in the foreign exchange markets, the results are mostly the same as those of Model 1, though the policy effects of the BOE and BOJ on their corresponding regional economies, becomes more apparent. The currency of the European countries, such as Denmark, Norway, and Sweden, now depreciate significantly, with respect to the monetary easing by the BOE. As for the BOJ, the persistence of an UMP shock on the Asian and Oceanian economies is

\footnotetext{
${ }^{5}$ Responses of Greek sovereign bond market, not reported to save space, are also qualitatively the same as those of Model 1.
} 
observed.

In summary, the results reveal the relatively small differences between the results of Models 1 and 2, in terms of the sign and magnitude of the effects of monetary easing policies by major central banks. However, the results also indicate some differences in the persistence of the effects, depending on the type of markets. Model 2 differs from Model 1 in that it models the monetary policy interactions among four central banks. The IRs calculated from Model 2, which considers the monetary policy interactions into account, suggests that Fed's monetary easing may generate room for other central banks to conduct less aggressive monetary easing. However, since Model 1 does not specify this offsetting effect correctly, the Fed's monetary easing effect could be underestimated in Model 1, particularly for the global equity and exchange market. If we allow the possible monetary policy interactions as per Model 2, the Fed's monetary policy easing effects on domestic markets tend to be less persistent, while those of the BOJ become more persistent for the domestic equity market and stronger for the domestic foreign exchange market. For the international sovereign and corporate bond markets, the effects are less persistent for the Fed and the ECB. In contrast, the monetary policy effects on the international equity and exchange markets tend to be more persistent in Model 2 for the Fed and BOJ, and stronger for the BOJ. These differences arguably demonstrate the possible importance of considering the monetary policy interactions.

\section{Conclusion}

After the GFC of 2008, major central banks, including the Fed, ECB, and BOE started initiating UMPs. The BOJ has conducted UMPs since 2001. Although there are several studies to assess the impacts of UMPs on the domestic macroeconomy and financial markets, a growing, but limited number of studies, examine the spillover effects of UMPs of major central banks on the international macroeconomy and financial markets. Against this backdrop, this paper empirically investigates whether and how the major central banks' UMPs transmit to international financial markets. To this end, we apply the GVAR model to 35 countries and one region, for the period March 2009 to July 2019. Our analysis includes the four major central banks, namely the Fed, ECB, BOE, and BOJ, taking the global spillover effects of their UMPs and possible interactions of their UMPs into account, making our analysis rather unique and insightful compared to the previous studies.

Our empirical results indicated that the UMPs of major central banks have expected easing effects on all domestic financial markets. The effects of the Fed are significant and persistent for all markets, while those of the ECB are significant for all markets, but not persistent for bond markets. However, the effects of the BOE and BOJ are less significant and persistent. 
Our results also suggested that the Fed's monetary easing has had significant impacts on the regional and Asian bond markets, and global equity, and foreign exchange markets. The ECB's policies seem to have stronger and broader effects on the global bond markets, compared to other central banks, but weaker and less persistent effects on the global equity markets, than the Fed. Generally, our results showed that the BOE's policy shock has little effect on the global financial market, except the Greek sovereign bond markets, which are boosted by the UMPs of all four central banks. Moreover, the BOJ demonstrated significant impacts on global equity markets and Asian bond and exchange rate markets.

Our analysis also revealed some evidence of monetary policy coordination and/or interference among the four major central banks. For many cases, one central bank's monetary easing seemed to help another central bank conduct less aggressive monetary easing, saving some room to execute further monetary easing. One notable exception was the BOE's reaction to the ECB's monetary easing, showing the tendency of the BOE to conduct similar monetary easing policies as that of the ECB. Generally, these monetary policy interactions did not affect the sign and magnitude of the effects of monetary easing policies by major central banks. However, the results also indicated some differences in the persistence of the monetary policy effects, depending on the type of markets. For the sovereign and corporate bond markets, the effects are less persistent for the Fed and the ECB, while those on the international equity and foreign exchange markets tend to be more persistent, particularly for those effects by the Fed and the BOJ. These differences arguably demonstrate the possible importance of taking the monetary policy interactions into account. 


\section{Appendix}

\section{Data Source and Data Construction}

- Shadow Rate: The month-end Shadow Short Rate (SSR), estimated for the US, the eurozone area, Japan, and the UK based on Krippner (2013) and his following research is used as an indicator of monetary policy. Data is available from https://www.rbnz.govt.nz/. The unit of original data is percentage.

- Sovereign Bond Index: The month-end S\&P Sovereign Bond Index (SBI), total rate of return, provided by SPDJ index. $s_{i t}$ is constructed as $s_{i t}=\log \left(\mathrm{SBI}_{i t}\right)$.

- Corporate Bond Index: The month-end S\&P Corporate Bond Index (CBI), total rate of return, provided by SPDJ index. $c_{i t}$ is constructed as $c_{i t}=\log \left(\mathrm{CBI}_{i t}\right)$.

- Equity Price Index: The month-end S\&P BMI Price Index (EI), downloaded from DataStream. One exception is Colombia (COL), where the original data was not complete. Thus, MSCI Price Index is used instead. $q_{i t}$ is constructed as $q_{i t}=\log \left(\mathrm{EI}_{i t}\right)$.

- Exchange Rates: Domestic Currency per US Dollar, End of Period, downloaded from IFS. The original data is inversed before taking a logarithm of it in order to construct $e_{i t}$.

Both bond and equity variables are the total return indices, and they are denominated in the local currency units. More precisely, the total return indices of bonds are calculated from the sum of interest returns and price returns. Similarly, the total return index of equity is constructed from the sum of dividend and price returns. Note that all the financial variables are in nominal terms. We do not adjust for inflation. 


\section{References}

Anaya, P., Hachula, M., and Offermanns, C. J. (2017). Spillovers of US unconventional monetary policy to emerging markets: The role of capital flows. Journal of International Money and Finance, 73:275-295.

Bauer, M. D. and Neely, C. J. (2014). International channels of the Fed's unconventional monetary policy. Journal of International Money and Finance, 9(2):165-212.

Bauer, M. D. and Rudebusch, G. D. (2014). The signaling channel for Federal Reserve bond purchases. International Journal of Central Banking, 10(3):233-289.

Bauer, M. D. and Rudebusch, G. D. (2016). Monetary policy expectations at the zero lower bound. Journal of Money, Credit and Banking, 48(7):1439-1465.

Bullard, J. (2012). Shadow interest rates and the stance of US monetary policy. Presentation at the Center for Finance and Accounting Research Annual Corporate Finance Conference, Washington University in St. Louis.

Burriel, P. and Galesi, A. (2018). Uncovering the heterogeneous effects of ECB unconventional monetary policies across euro area countries. European Economic Review, 101:210-229.

Chen, Q., Filardo, A., He, D., and Zhu, F. (2016). Financial crisis, US unconventional monetary policy and international spillovers. Journal of International Money and Finance, 67:62-81.

Chen, Q., Lombardi, M. J., Ross, A., and Zhu, F. (2017). Global impact of US and euro area unconventional monetary policies: A comparison. BIS Working Paper, No. 610.

Christiano, L. J., Eichenbaum, M., and Evans, C. L. (1999). Monetary policy shocks: What have we learned and to what end? In Taylor, J. B. and Woodford, M., editors, Handbook of Macroeconomics, pages 65-148. Elsevier Science.

Curdia, V. and Woodford, M. (2011). The central-bank balance sheet as an instrument of monetary policy. Journal of Monetary Economics, 58(1):54-79.

D'Amico, S. and King, T. B. (2013). Flow and stock effects of large-scale treasury purchases: Evidence on the importance of local supply. Journal of Financial Economics, 108(2):425-448.

Dedola, L., Rivolta, G., and Stracca, L. (2017). If the Fed sneezes, who catches a cold? Journal of International Economics, 108:S23-S41. 
Dees, S., di Mauro, F., Pesaran, M. H., and Smith, L. V. (2007a). Exploring the international linkages of the euro area: a global VAR analysis. Journal of Applied Econometrics, 22:1-38.

Dees, S., Holly, S., Pesaran, M. H., and Smith, L. V. (2007b). Long-run macroeconomic relations in the global economy. Economics: The Open-Access, Open-Assessment E-Journal, $1(3): 1-56$.

Dekle, R. and Hamada, K. (2015). Japanese monetary policy and international spillovers. Journal of International Money and Finance, 52:175-199.

Ganelli, G. and Tawk, N. (2019). Spillovers from Japan's unconventional monetary policy: A global VAR approach. Economic Modelling, 77(C):147-163.

Georgiadis, G. (2016). Determinants of global spillovers from US monetary policy. Journal of International Money and Finance, 67(C):41-61.

Gertler, M. and Karadi, P. (2013). QE 1 vs. 2 vs. 3...: A framework for analyzing largescale asset purchases as a monetary policy tool. International Journal of Central Banking, $9(\mathrm{~S} 1): 5-53$.

Haldane, A. G., Roberts-Sklar, M., Wieladek, T., and Young, C. (2016). QE: The story so far. Staff Working Paper 624, Bank of England.

Ihrig, J., Klee, E., Li, C., Wei, M., and Kachovec, J. (2018). Expectations about the Federal Reserve's balance sheet and the term structure of interest rates. International Journal of Central Banking, 14(2):341-391.

Inoue, T. and Okimoto, T. (2019). How does unconventional monetary policy affect the global financial markets?: Evaluating policy effects by global VAR models. RIETI Discussion Paper, 19-E-03.

Kenourgios, D., Drakonaki, E., and Dimitriou, D. (2019). ECB's unconventional monetary policy and cross-financial-market correlation dynamics. North American Journal of Economics and Finance, 50:101045.

Krippner, L. (2013). Measuring the stance of monetary policy in zero lower bound environments. Economics Letters, 118(1):135-138.

Krishnamurthy, A. and Vissing-Jorgensen, A. (2011). The effects of quantitative easing on interest rates: channels and implications for policy. Brookings Papers on Economic Activity, Fall 2011:215-287. 
Nelson, C. and Siegel, A. F. (1987). Parsimonious modeling of yield curves. Journal of Business, 60(4):473-489.

Pesaran, M. H., Schuermann, T., and Weiner, S. M. (2004). Modeling regional interdependencies using a global error-correcting macroeconomic model. Journal of Business $\&$ Economic Statistics, 22(2):129-162.

Rey, H. (2016). International channels of transmission of monetary policy and the mundellian trilemma. IMF Economic Review, 64:6-35.

Sugimoto, K. and Matsuki, T. (2019). International spillovers into asian stock markets under the unconventional monetary policies of advanced countries. Journal of the Japanese and International Economies, 52:171-188.

Swanson, E. T. (2018). Measuring the effects of Federal Reserve forward guidance and asset purchases on financial markets. NBER Working Paper 23311.

Wu, J. C. and Xia, F. D. (2016). Measuring the macroeconomic impact of monetary policy at the zero lower bound. Journal of Money, Credit and Banking, 48(2-3):253-291. 
Table 1: A list of sample region/country/economy

\begin{tabular}{lccc}
\hline Region/Country/Economy names & 3digit & Region/Country/Economy names & 3digit \\
\hline American region (5) & & European region (5) & dnk \\
Canada & can & Denmark & nor \\
Chile & chl & Norway & swe \\
Colombia & col & Sweden & che \\
Mexico & mex & Switzerland & gbr \\
United States & usa & United Kingdom & \\
& & & aus \\
Eurozone and its member countries (12) & & Asian and Oceanian region (13) & chn \\
Eurozone & emu & Australia & hkg \\
Austria & aut & China & ind \\
Belgium & bel & Hong Kong & idn \\
Finland & fin & India & jpn \\
France & fra & Indonesia & kor \\
Germany & deu & Japan & mys \\
Greece & grc & Korea, Republic of & nzl \\
Ireland & irl & Malaysia & phl \\
Italy & ita & New Zealand & sgp \\
Netherlands & nld & Philippines & twn \\
Portugal & prt & Singapore & tha \\
Spain & esp & Taiwan, Province of China & \\
& & Thailand & \\
& & African region (1) & South Africa \\
& & & zaf \\
& & &
\end{tabular}

Notes: Horizontal position of countries/economies in Figures 2, 3, 4, 5, 8, 9, 10, and 11 are ordered as they are listed in this table, unless otherwise noted at their footnotes. The figure in parenthesis indicates the number of individual VAR models, estimated for each region. 
Table 2: Variables Specification of the economy-specific VARX* Models

\begin{tabular}{ccccc}
\hline \multicolumn{2}{c}{ Small Economies } & & \multicolumn{2}{c}{ UK/Japan model } \\
\cline { 1 - 2 } Domestic & Foreign & & Domestic & Foreign \\
\cline { 1 - 1 }$s_{i t}$ & $s_{i t}^{*}$ & & $m_{i t}$ & {$\left[m_{i t}^{*}\right]$} \\
$\left(c_{i t}\right)$ & $c_{i t}^{*}$ & & $c_{i t}$ & $c_{i t}^{*}$ \\
$q_{i t}$ & $q_{i t}^{*}$ & & $q_{i t}$ & $q_{i t}^{*}$ \\
$e_{i t}$ & & & $e_{i t}$ & \\
\hline
\end{tabular}

\begin{tabular}{|c|c|c|c|c|c|}
\hline \multicolumn{2}{|c|}{ EMU member } & \multicolumn{2}{|c|}{ EMU unit } & \multicolumn{2}{|c|}{ US model } \\
\hline Domestic & Foreign & Domestic & Foreign & Domestic & Foreign \\
\hline & $m_{\mathrm{E}, t}$ & $m_{\mathrm{E}, t}$ & {$\left[m_{\mathrm{E}, t}^{*}\right]$} & $m_{\mathrm{U}, t}$ & {$\left[m_{\mathrm{U}, t}^{*}\right]$} \\
\hline$s_{i t}$ & $s_{i t}^{*}$ & & $\tilde{s}_{\mathrm{E}, t}$ & $s_{\mathrm{U}, t}$ & \\
\hline & $c_{i t}^{*}, c_{\mathrm{E}, t}$ & $c_{\mathrm{E}, t}$ & & $c_{\mathrm{U}, t}$ & \\
\hline$q_{i t}$ & $q_{i t}^{*}$ & & $\tilde{q}_{\mathrm{E}, t}^{*}$ & $q_{\mathrm{U}, t}$ & \\
\hline & $e_{\mathrm{E}, t}$ & $e_{\mathrm{E}, t}$ & & & $e_{\mathrm{U}, t}^{*}$ \\
\hline
\end{tabular}

Notes: Variable in ( ) is included in the model if data is available. Monetary policy indicator variable in [ ] is not included in Model-1, but included in Model 2.

Table 3: Responses of Greek sovereign bond market to an unexpected $0.25 \%$ drop of shadow rate, Model-1

\begin{tabular}{ccccccc}
\hline & \multicolumn{3}{c}{1 month } & \multicolumn{3}{c}{3 months } \\
& $16 \%$ & $50 \%$ & $84 \%$ & $16 \%$ & $50 \%$ & $84 \%$ \\
\hline Fed & 0.90 & 3.44 & 13.33 & 1.58 & 5.63 & 21.33 \\
ECB & -1.51 & 1.61 & 2.82 & -4.34 & 1.42 & 4.33 \\
BOE & 0.30 & 0.87 & 3.12 & 0.10 & 0.68 & 2.45 \\
BOJ & 0.95 & 2.52 & 8.83 & 1.05 & 3.09 & 10.64 \\
\hline
\end{tabular}


Figure 1: Responses of the domestic financial markets to an unexpected $0.25 \%$ point drop of own shadow rate
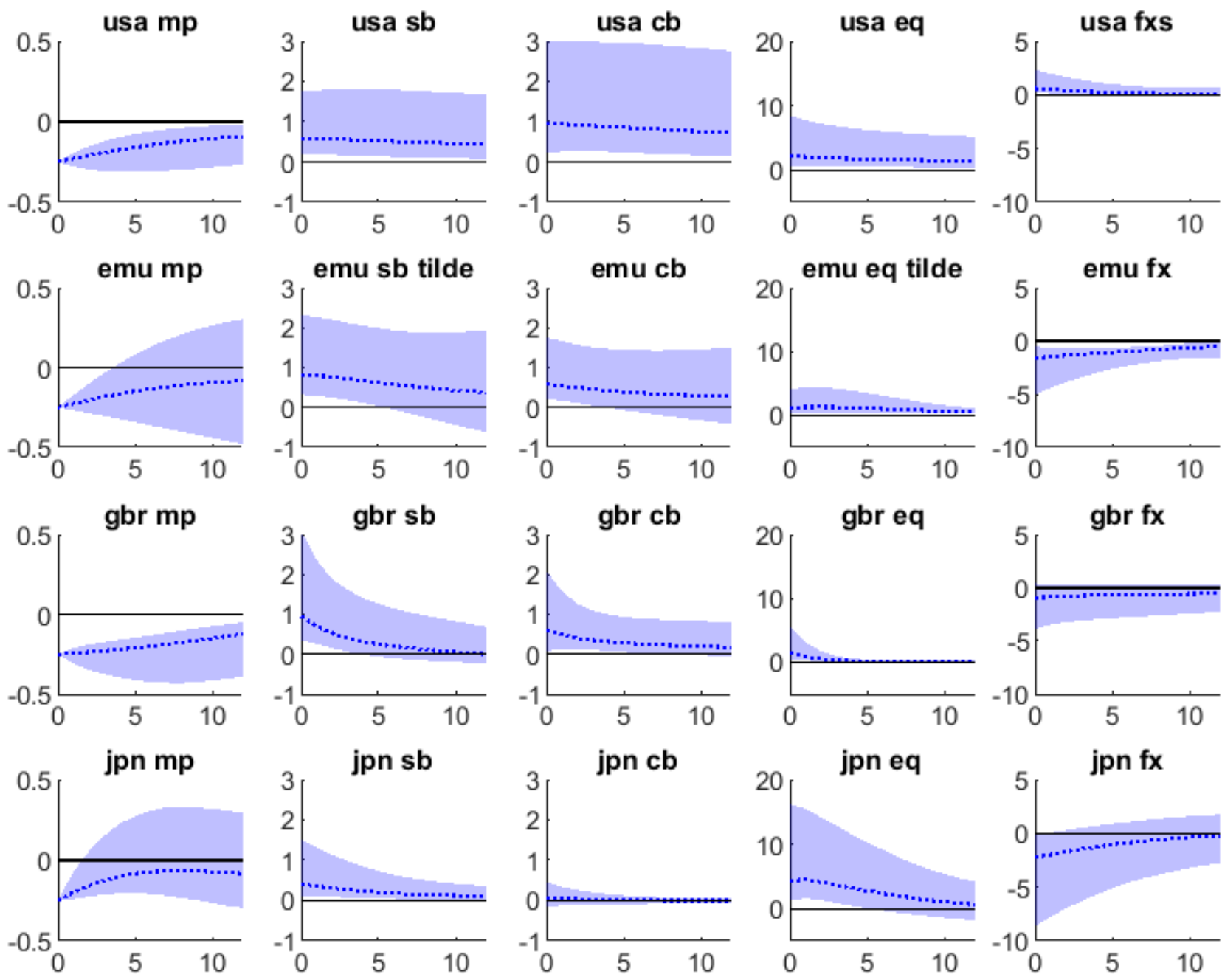

Note: From the top to the bottom, the responses to US Federal Reserve's shock, the European Central Bank's shock, the Bank of England's shock, and the Bank of Japan's shock are plotted. For the mnemonic used in these figures, see Table 1. The number for a valid draw is 10,000. The blue dotted lines correspond to the median value, the shaded areas correspond to upper/lower $16 \%$ of the distribution. 
Figure 2: Responses of the global sovereign bond markets to an unexpected $0.25 \%$ drop of shadow rate

(a) Federal Reserve
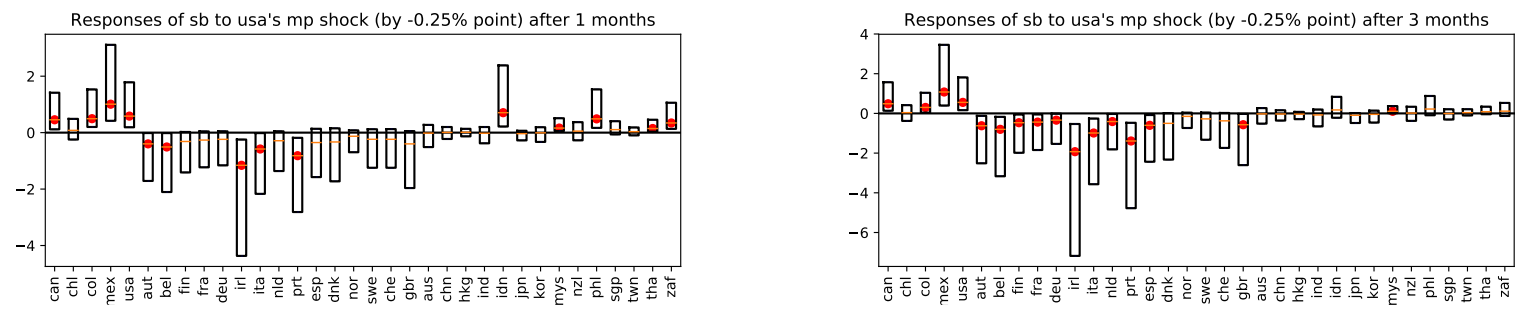

(b) European Central Bank
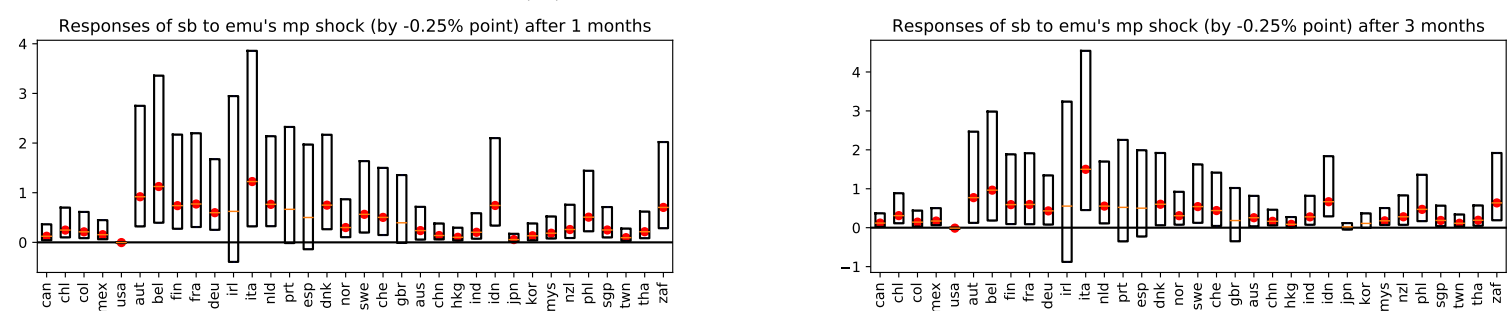

(c) Bank of England
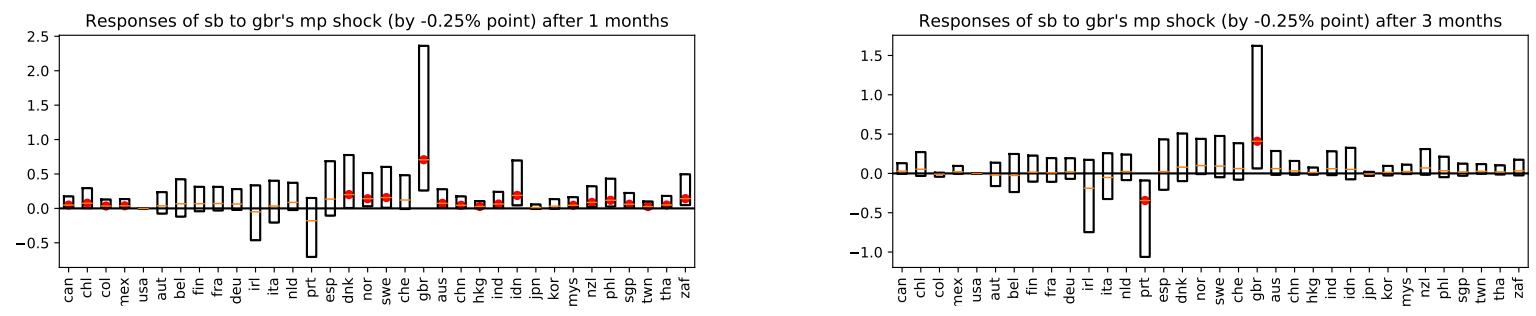

(d) Bank of Japan
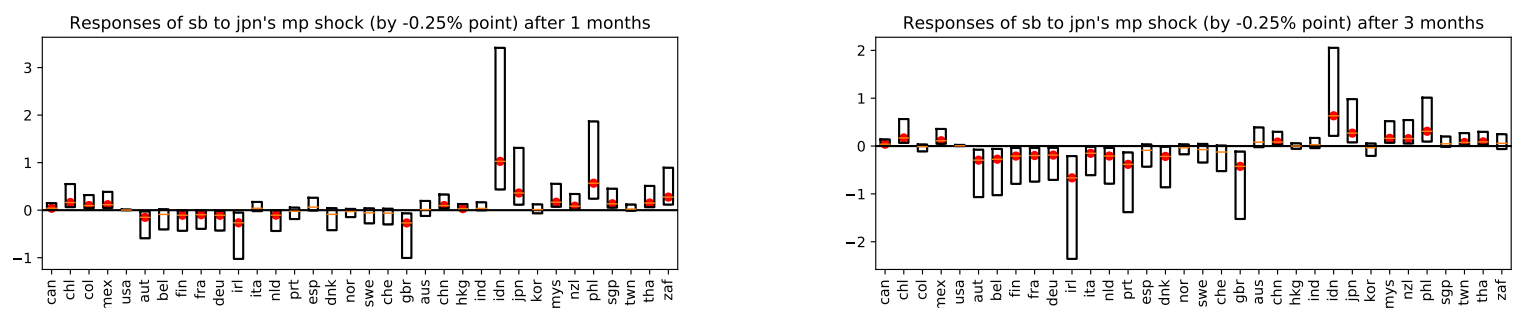

Note: For the mnemonic of the horizontal axis in these figures, see Table 1 . The number for a valid draw is 10,000 . The top and the bottom of the box corresponds to upper/lower $16 \%$ of the distribution, and the orange line in the box shows the median response. If the circle is red, the response is significant at $16 \%$ level (by one-sided test). The Greek responses are exceptionally large in magnitude, possibly due to the Greek government-debt crisis, which suppresses the responses of other countries. For this reason, the responses of Greece are omitted from the plots. 
Figure 3: Responses of the global corporate bond markets to an unexpected $0.25 \%$ drop of shadow rate

(a) Federal Reserve
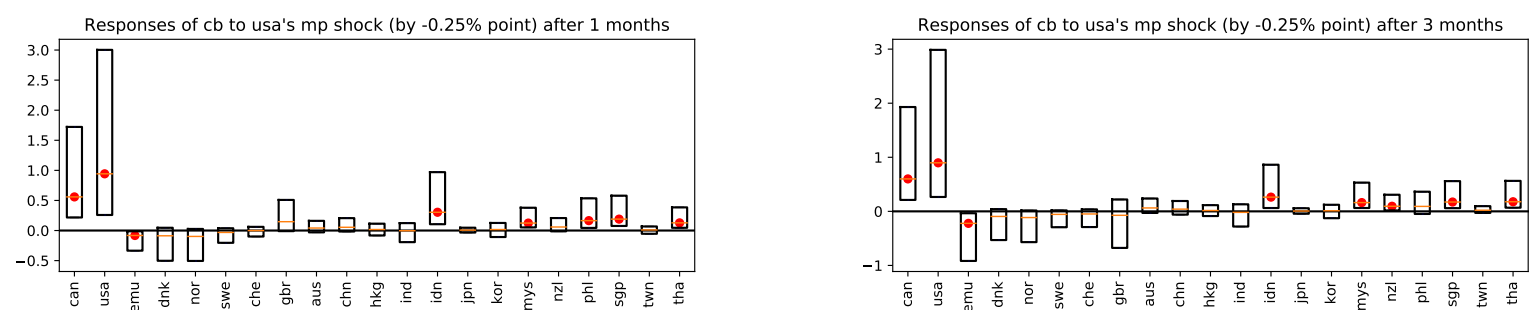

(b) European Central Bank
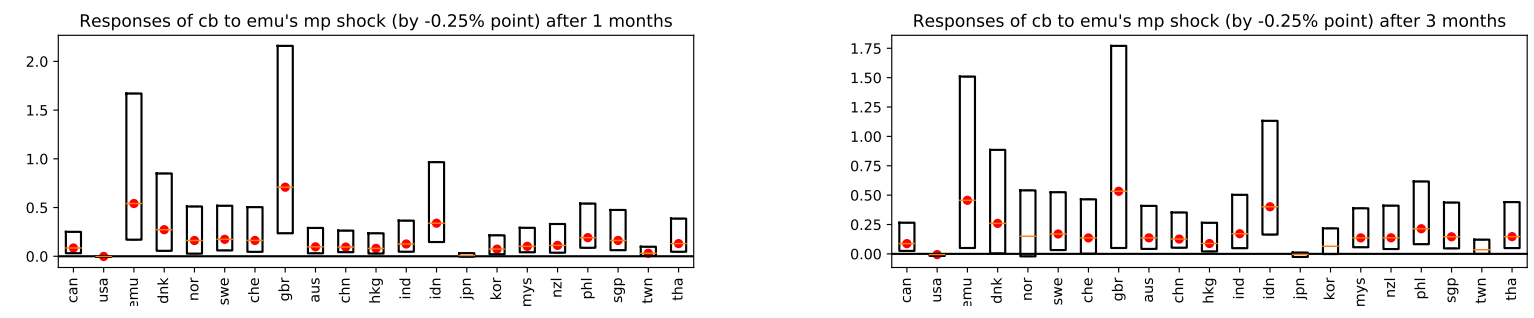

(c) Bank of England
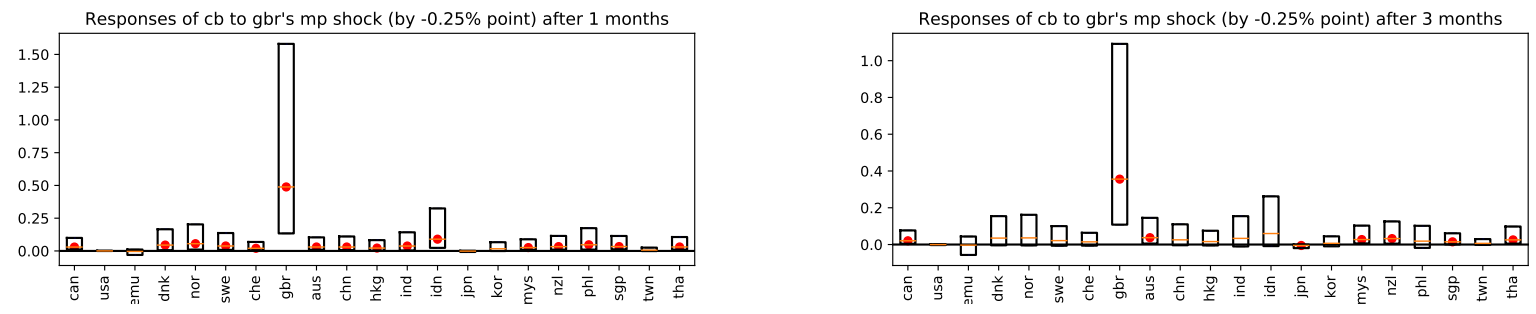

(d) Bank of Japan
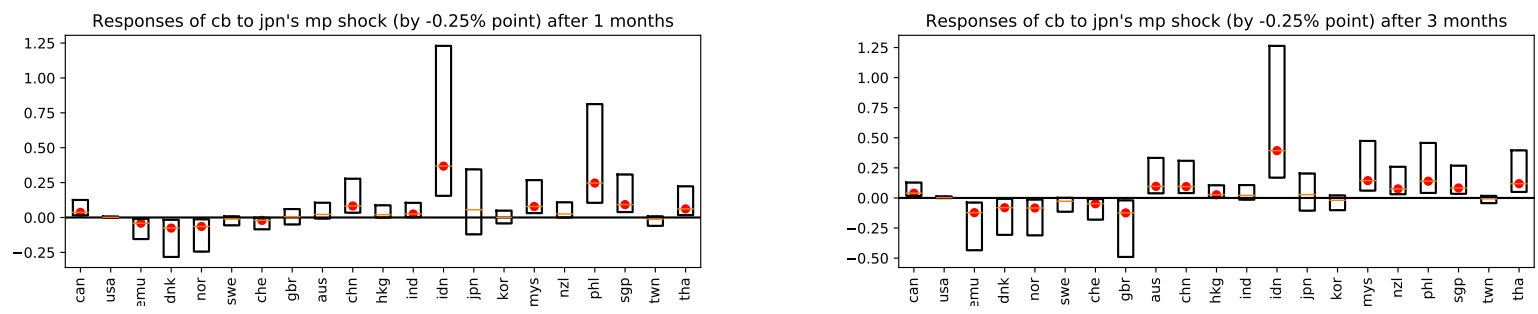

Note: See footnote of Figure 2. The corporate bond price indexes are missing for Chile, Colombia, Mexico, South Africa, and eurozone member countries, thus they are excluded from the plots. 
Figure 4: Responses of the global equity markets to an unexpected $0.25 \%$ drop of shadow rate (a) Federal Reserve
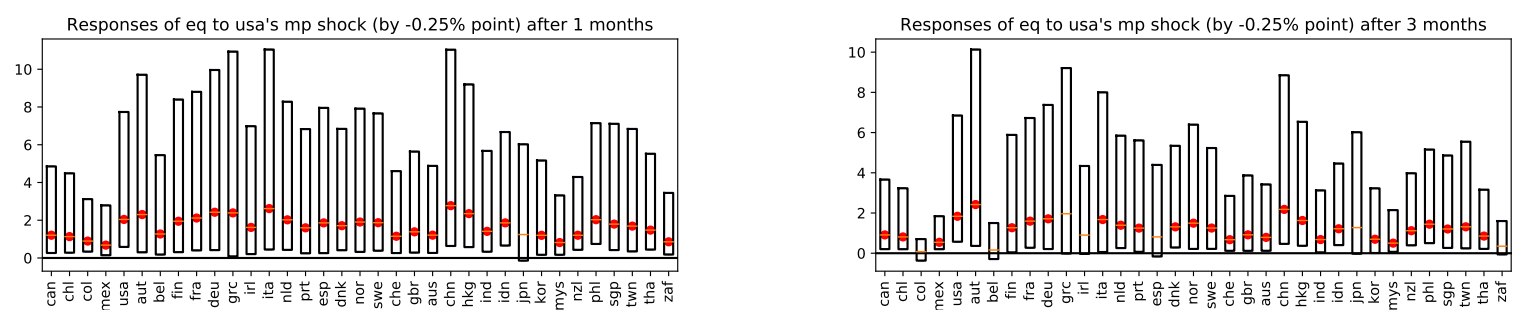

(b) European Central Bank
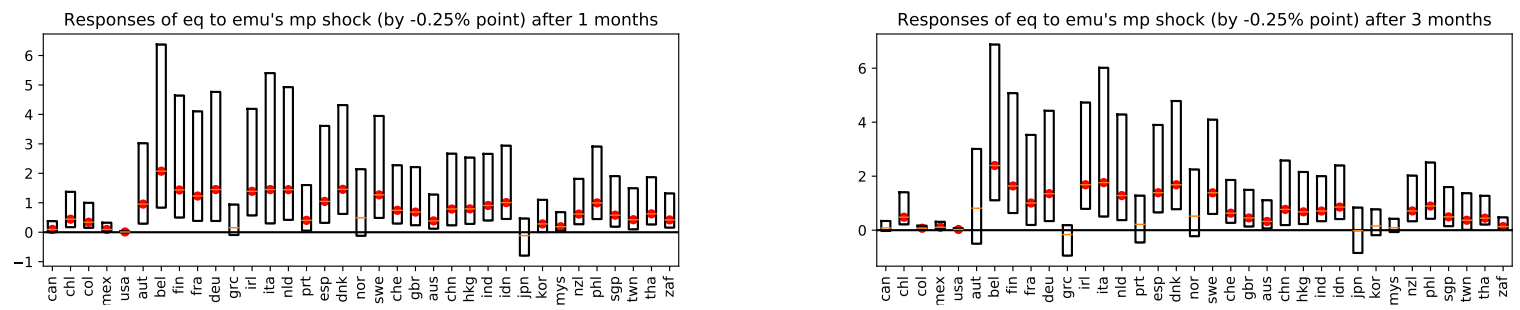

(c) Bank of England
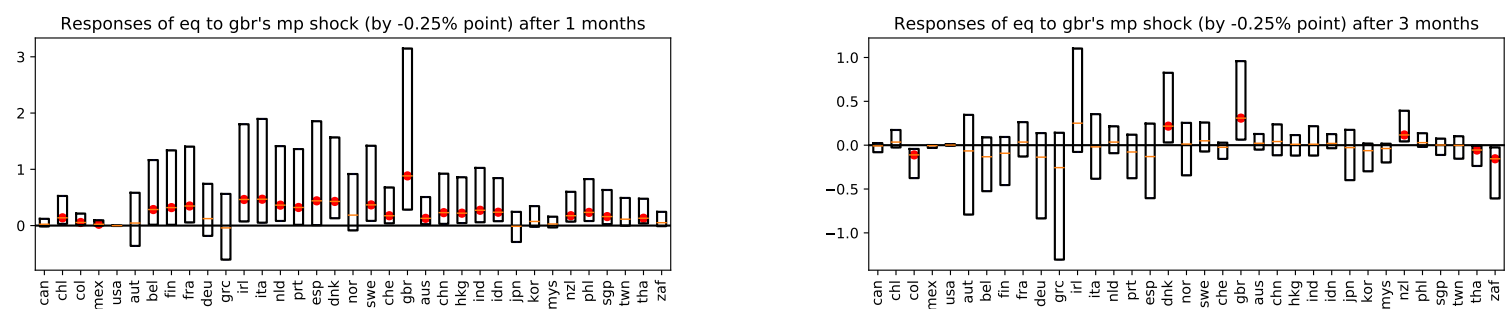

(d) Bank of Japan
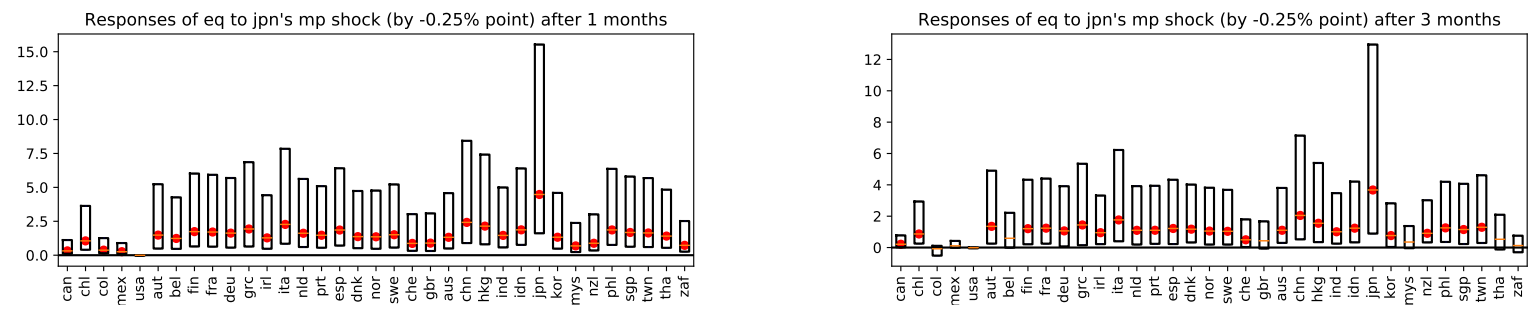

Note: See footnote of Figure 2. Note that the responses of Greece are included. 
Figure 5: Responses of the global foreign exchange markets to an unexpected $0.25 \%$ drop of shadow rate

(a) Federal Reserve
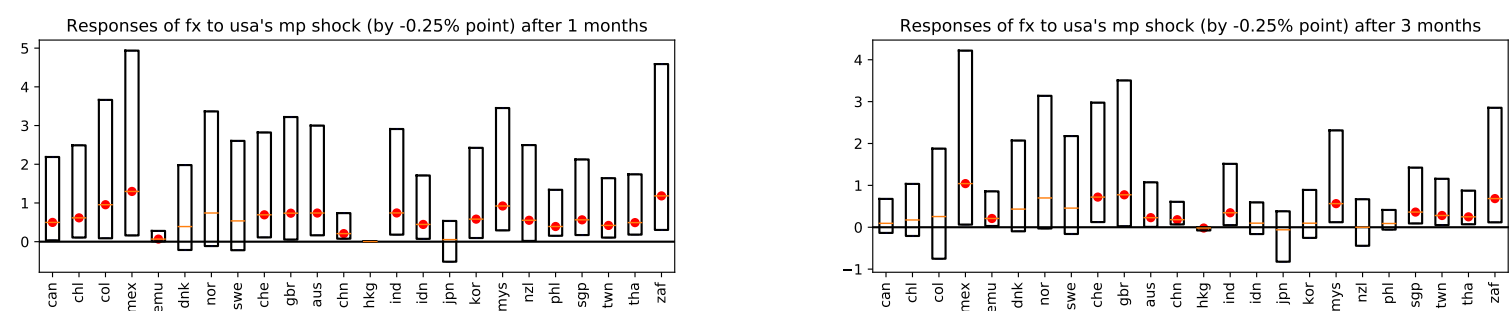

(b) European Central Bank
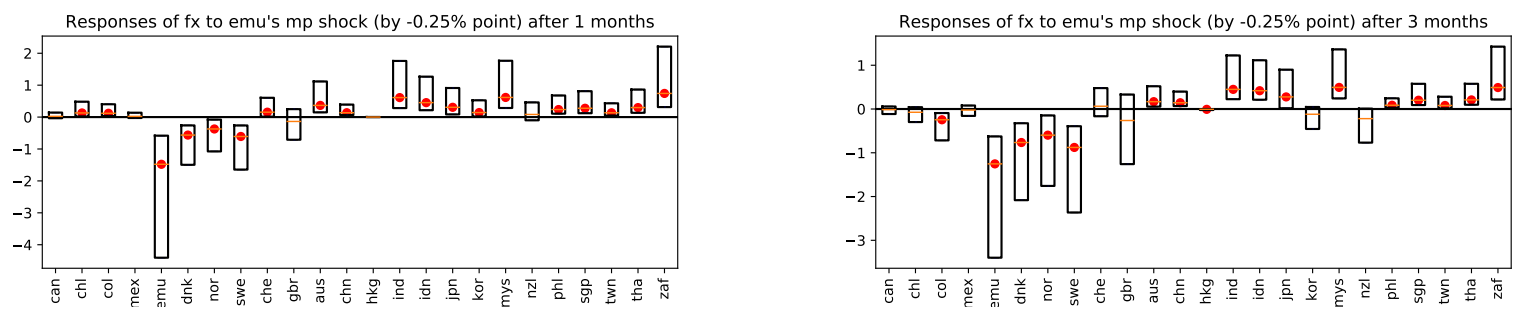

(c) Bank of England
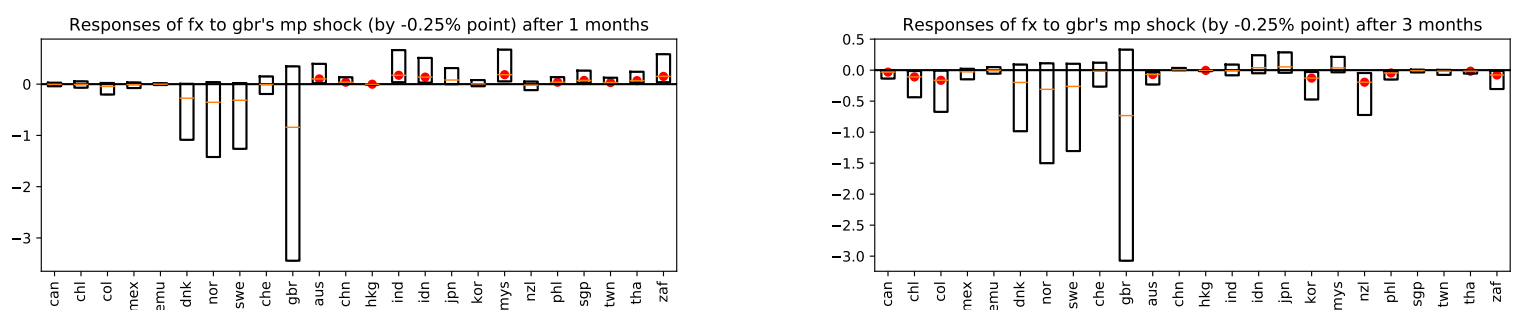

(d) Bank of Japan
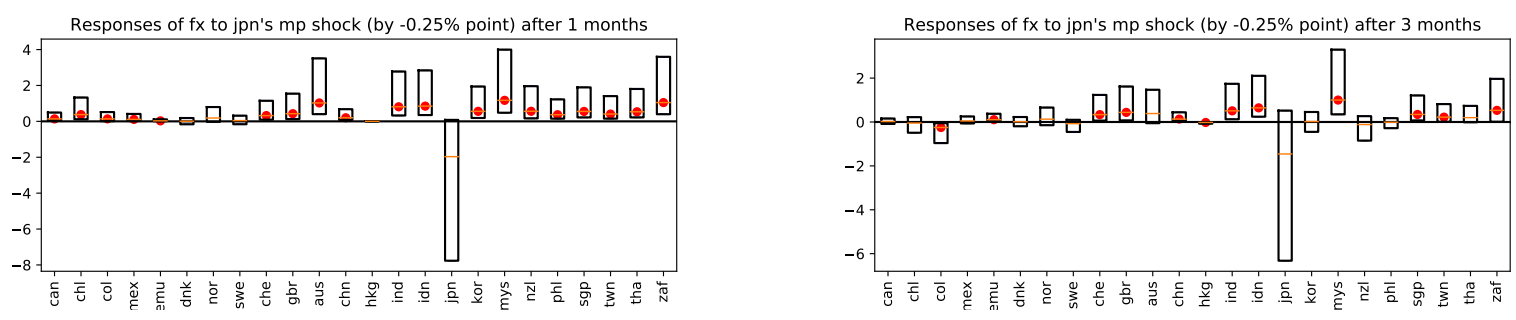

Note: See footnote of Figure 2. The eurozone member countries are excluded from the plots. 
Figure 6: Responses of counter parties' SSR (the size of shock: $0.25 \%$ point drop of SSR)
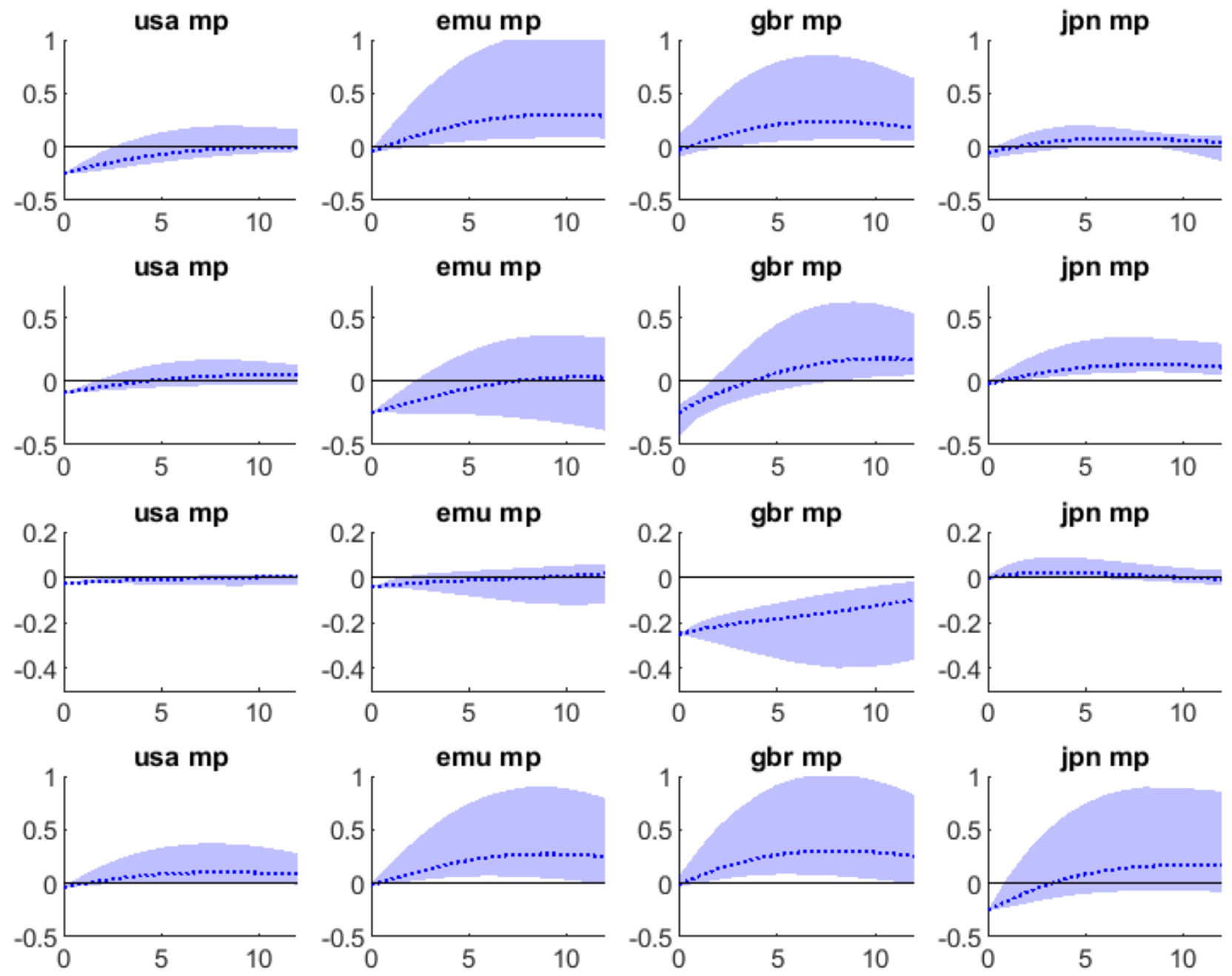

Note: From the top to the bottom, the responses to US Federal Reserve's shock, the European Central Bank's shock, the Bank of England's shock, and the Bank of Japan's shock are plotted. For the mnemonic used in these figures, see Table 1 . The number for a valid draw is 10,000. The blue dotted lines correspond to the median value, the shaded areas correspond to upper/lower $16 \%$ of the distribution. 
Figure 7: Responses of the domestic financial markets to an unexpected $0.25 \%$ point drop of own shadow rate
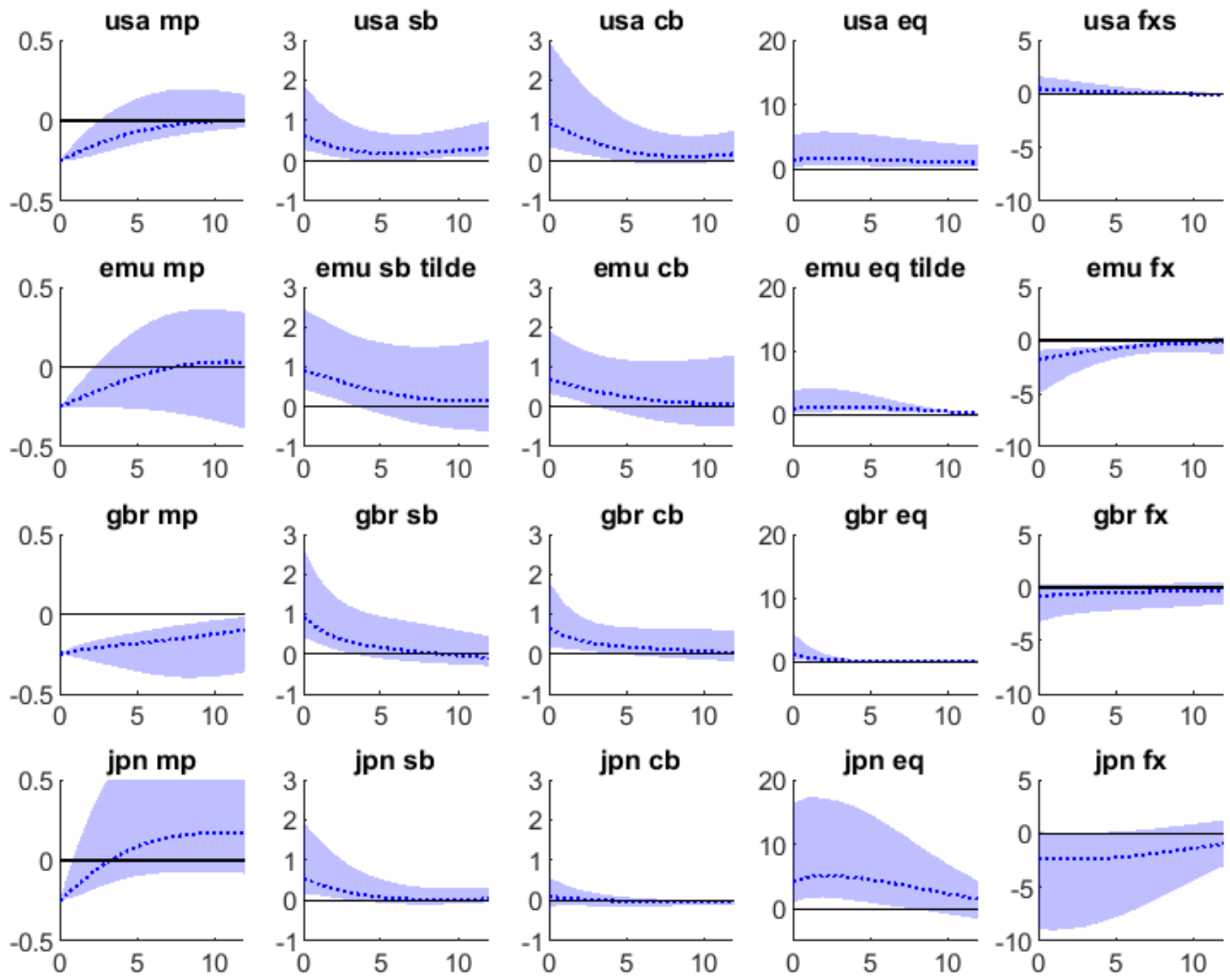

Note: From the top to the bottom, the responses to US Federal Reserve's shock, the European Central Bank's shock, the Bank of England's shock, and the Bank of Japan's shock are plotted. For the mnemonic used in these figures, see the footnote of Table 1 . The number for a valid draw is 10,000. The blue dotted lines correspond to the median value, the shaded areas correspond to upper/lower $16 \%$ of the distribution. 
Figure 8: Responses of the global sovereign bond markets to an unexpected $0.25 \%$ drop of shadow rate

(a) Federal Reserve
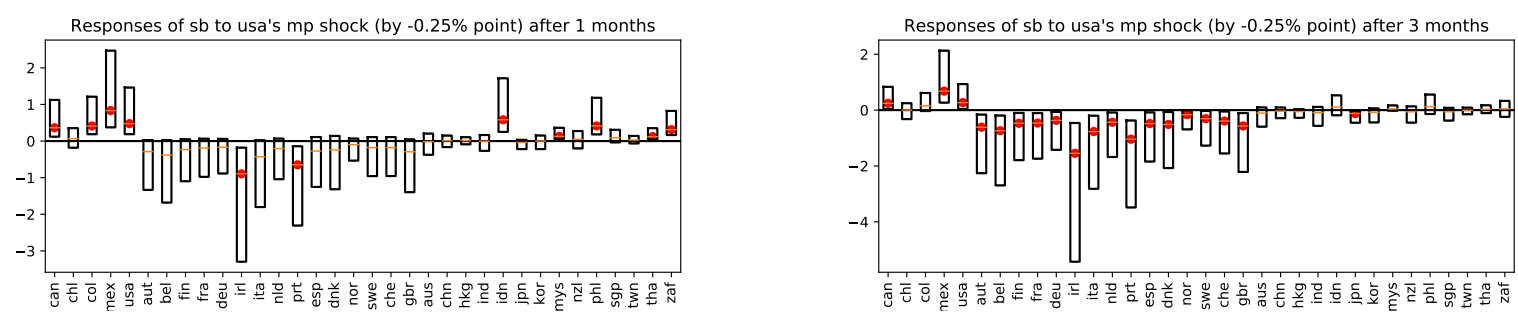

(b) European Central Bank
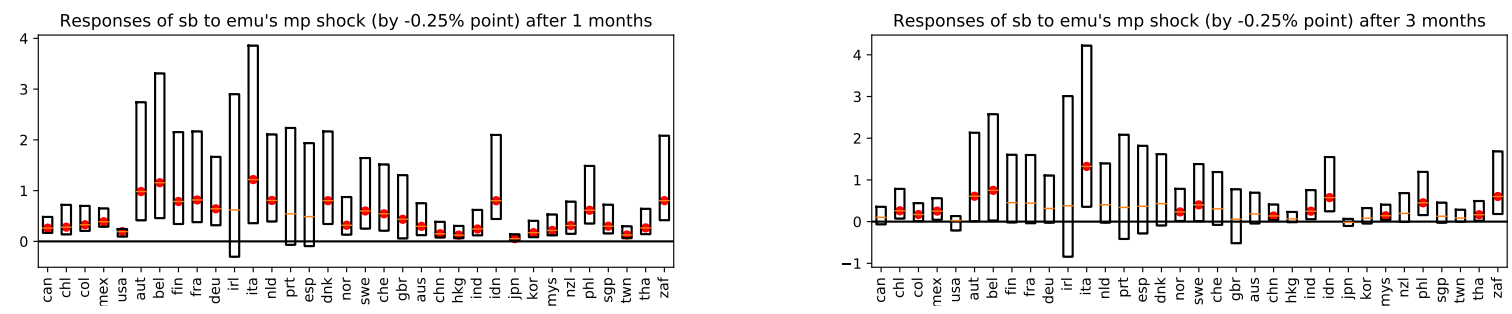

(c) Bank of England
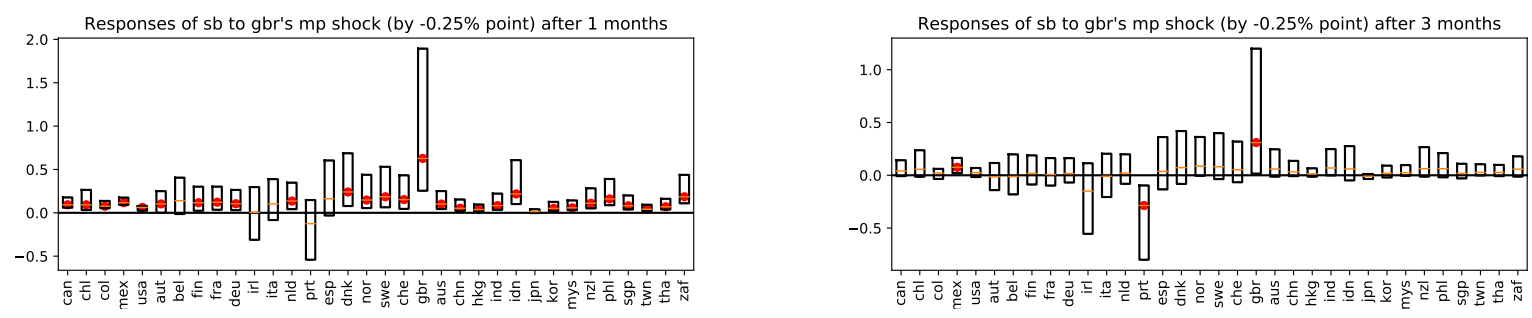

(d) Bank of Japan
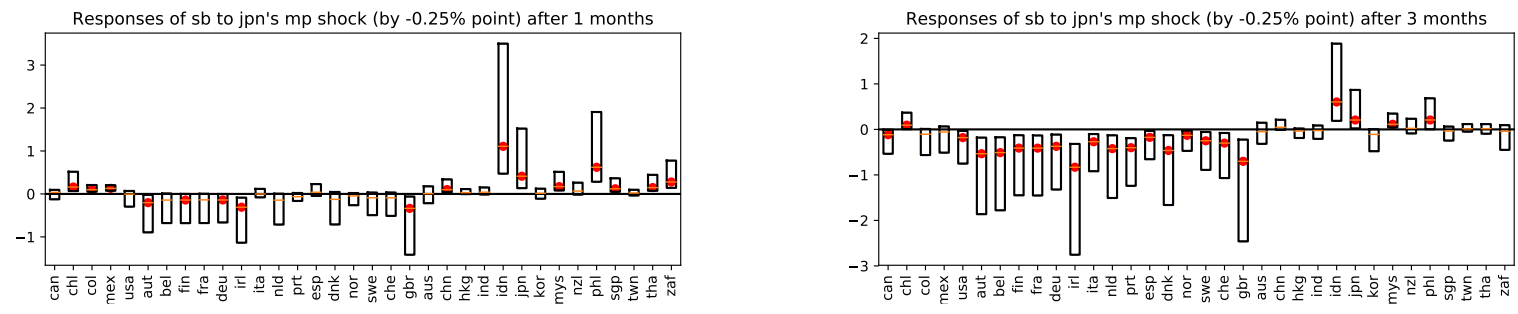

Note: See footnote of Figure 2. 
Figure 9: Responses of the global corporate bond markets to an unexpected $0.25 \%$ drop of shadow rate

(a) Federal Reserve
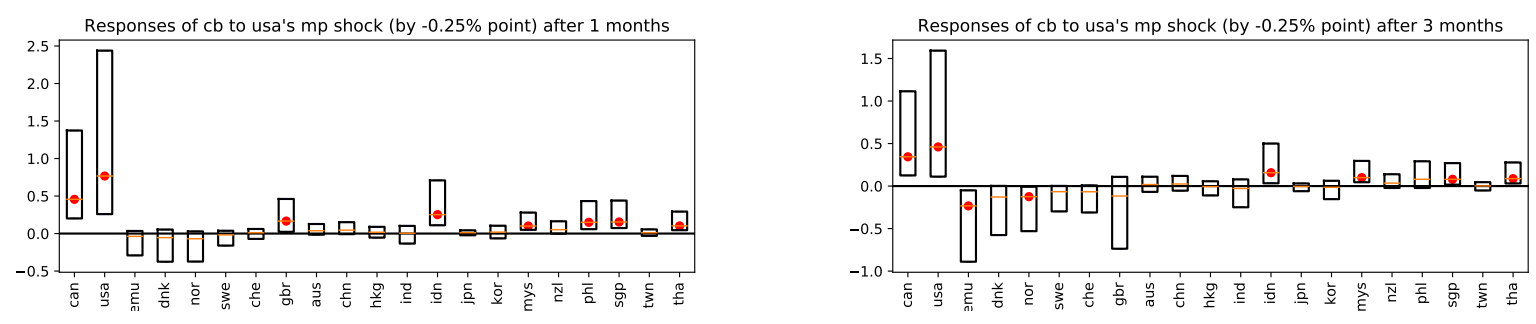

(b) European Central Bank
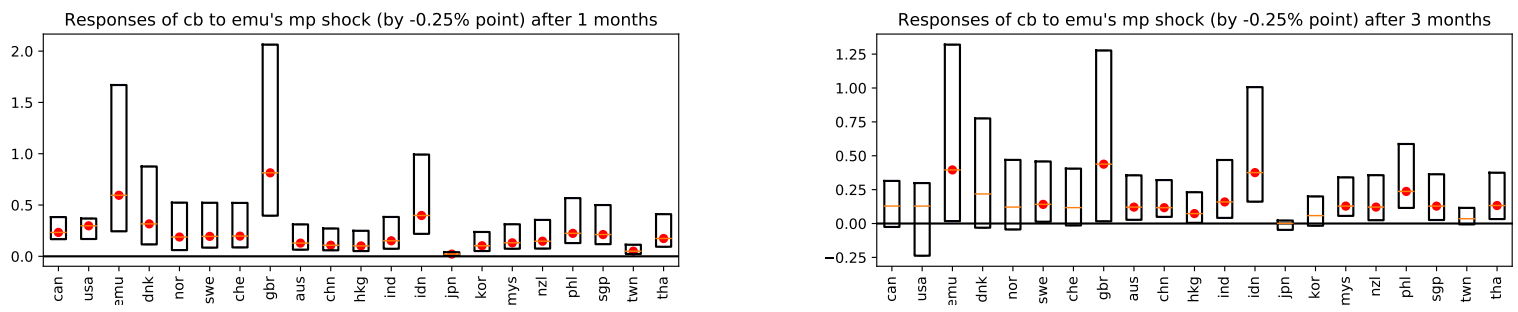

(c) Bank of England
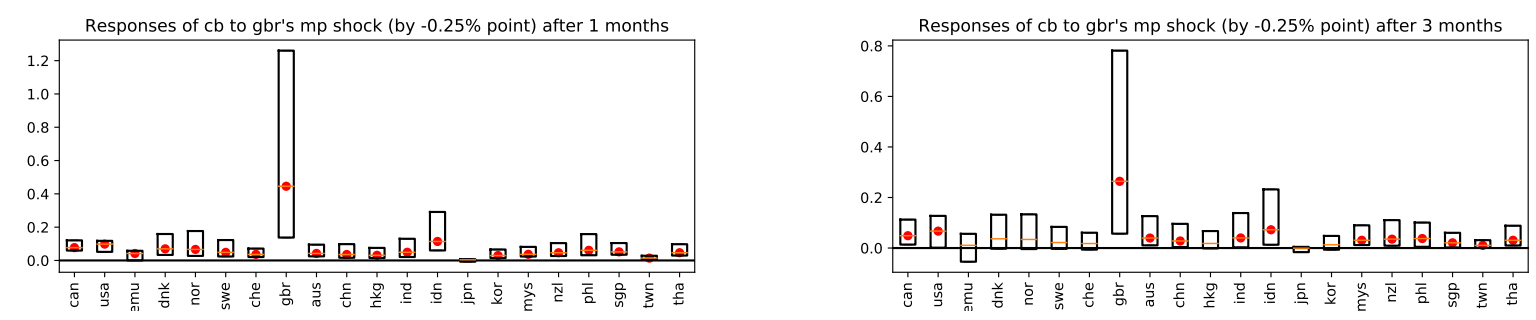

(d) Bank of Japan
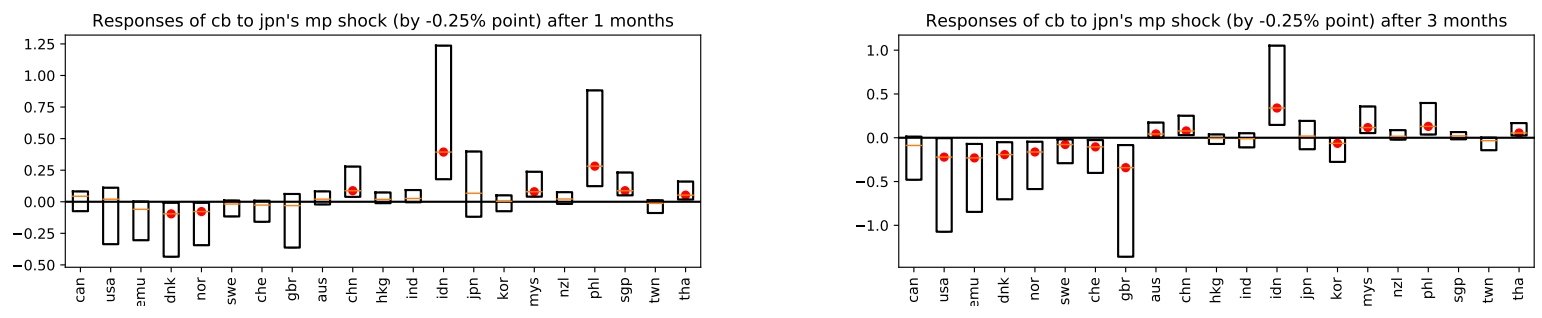

Note: See footnote of Figure 3. 
Figure 10: Responses of the global equity markets to an unexpected $0.25 \%$ drop of shadow rate

(a) Federal Reserve
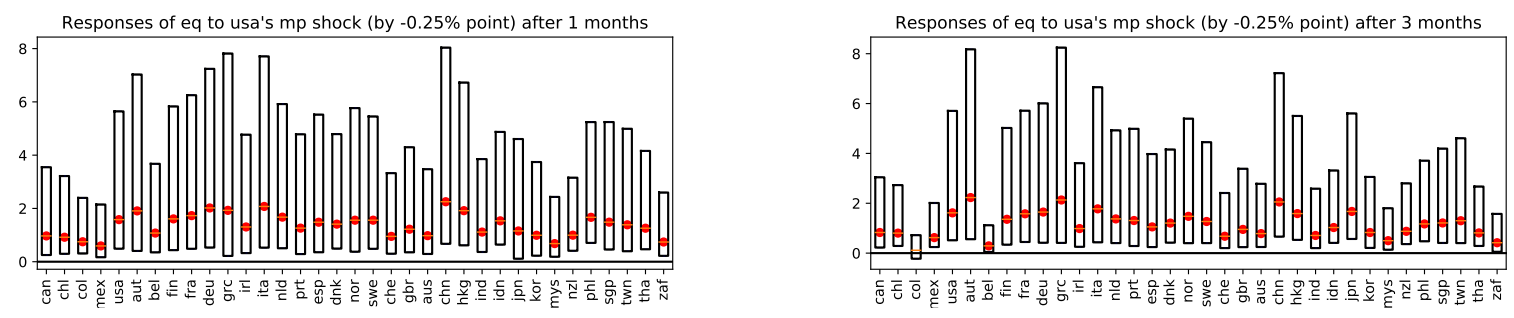

(b) European Central Bank
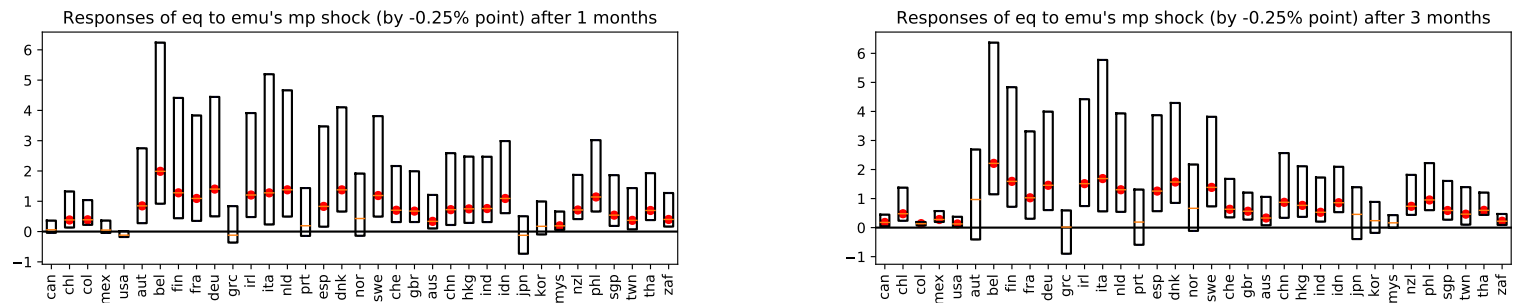

(c) Bank of England
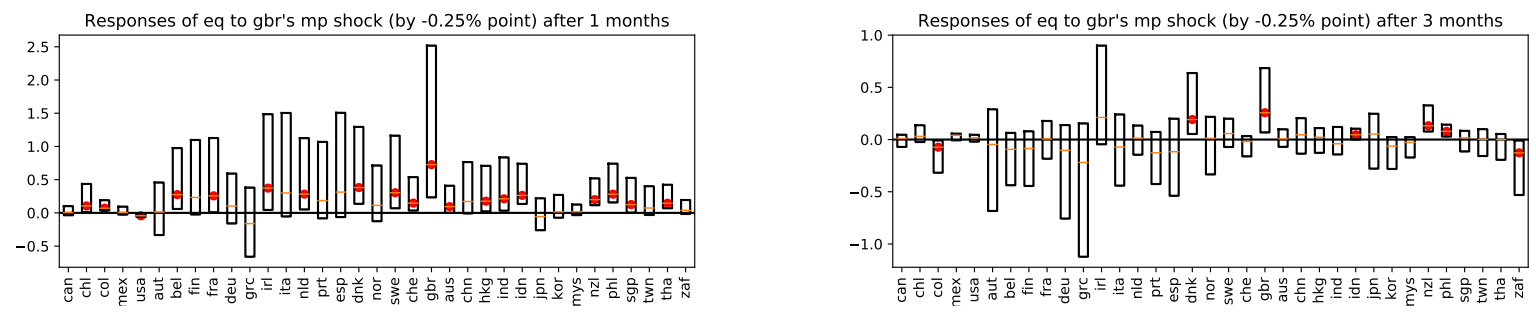

(d) Bank of Japan
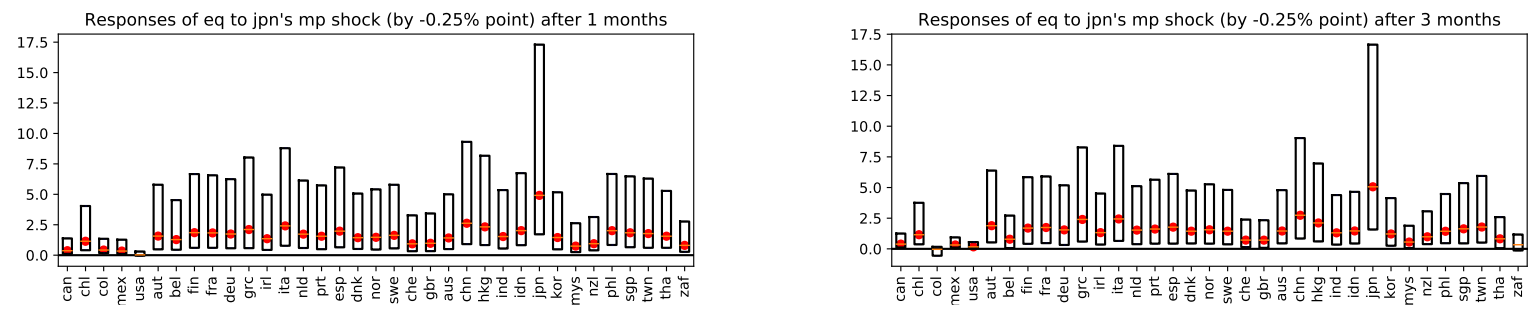

Note: See footnote of Figure 4. 
Figure 11: Responses of the global foreign exchange markets to an unexpected $0.25 \%$ drop of shadow rate

(a) Federal Reserve
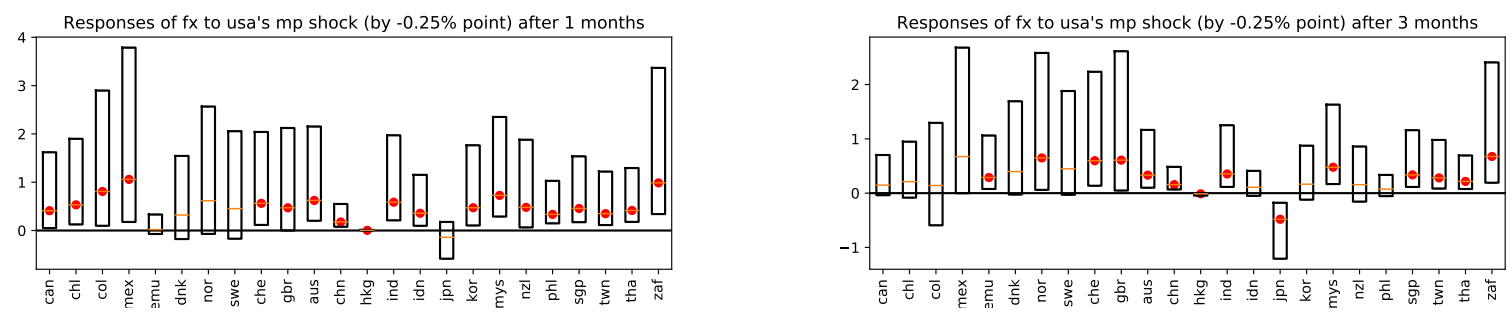

(b) European Central Bank
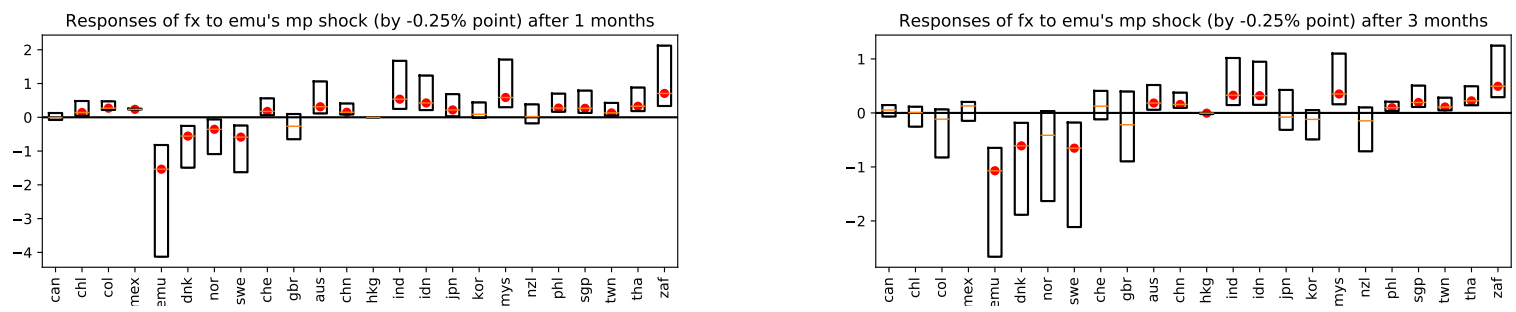

(c) Bank of England
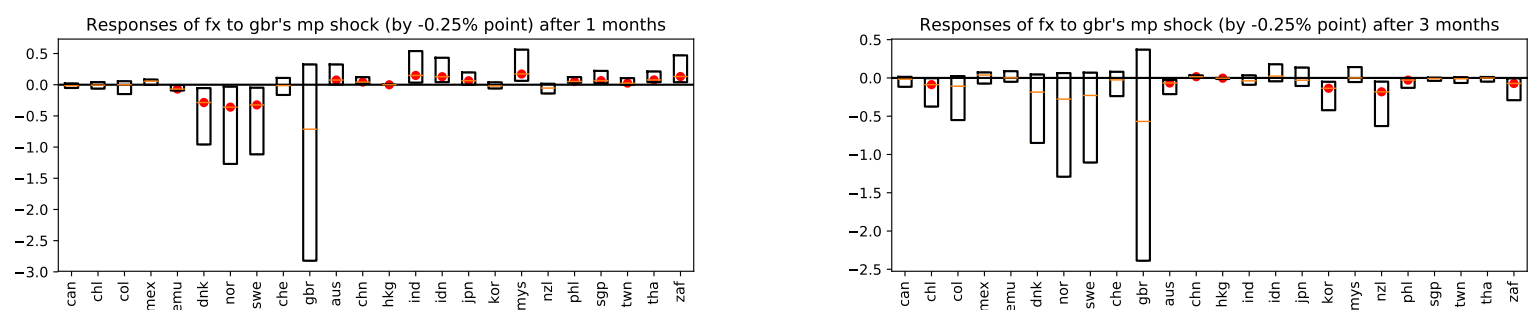

(d) Bank of Japan
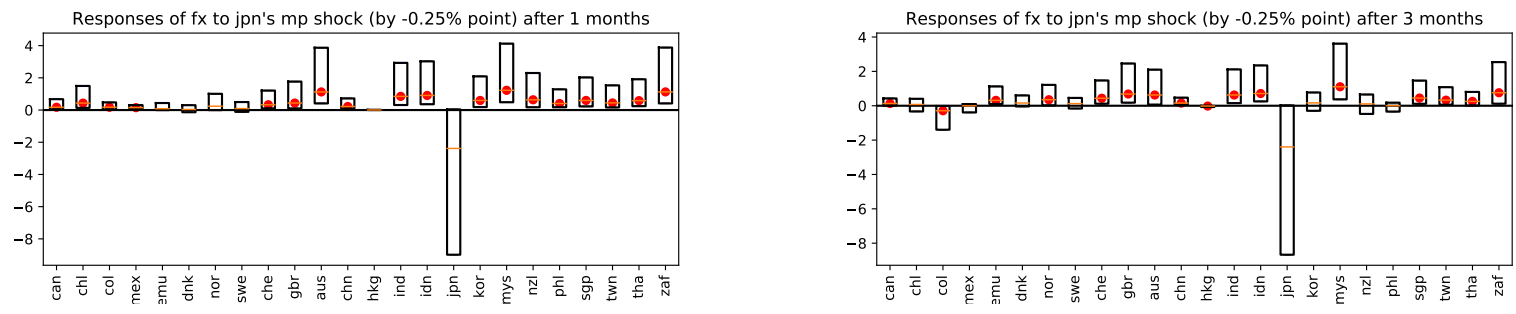

Note: See footnote of Figure 5. 


\section{Previous FFJ Discussion Papers}

\section{DP 20-04 (July 2020)}

"Characteristics of Bike taxis in African rural society: A case study of Dschang, West Cameroon", Makiko Sakai (Tokyo University of Foreign Studies), FFJ Visiting Researcher

\section{DP 20-03 (June 2020)}

"Decomposing Preference for Redistribution Beyond the Trans-Atlantic Perspective", Ryo Kambayashi (Hitotsubashi University), Sébastien Lechevalier (EHESS, CCJ-FFJ), Thanasak Jenmana (PSE)

\section{DP 20-02 (April 2020)}

"A Comparative Analysis of Autonomous Vehicle Policies among Korea, Japan, and France", Jeehoon Ki (KISTEP), 2018 FFJ/Renault Fellow

\section{DP 20-01 (March 2020)}

"Comparing the Development and Commercialization of Care Robots in the European Union and Japan", James Wright (Sheffield University), 2019 FFJ/Michelin Fellow

\section{DP 19-05 (November 2019)}

"Credit Guarantees and Zombie Firms: A Case Study of Small and Medium-Sized Enterprises in Japan", Scott Wilbur (Yale University), 2018 FFJ/ Banque de France Fellow

\section{DP 19-04 (October 2019)}

"Impact of R\&D Activities on Pricing Behaviors with Product Turnover", Yasushi Hara (Hitotsubashi University), 2018 FFJ/Michelin Fellow, Akiyuki Tonogi (Toyo University) \& Konomi Tonogi (Rissho University)

\section{DP 19-03 (September 2019)}

"From Agribusiness to Food Democracy. Comparative Study on Agricultural Policy and Organic Farming in France and in Japan", Shoichiro Takezawa (National Museum of Ethnology, Japan); 2018 FFJ/Air Liquide Fellow

\section{DP 19-02 (June 2019)}

"Legitimation of Income Inequality in Japan: A Comparison with South Korea and the United States", Shin Arita (The University of Tokyo), Kikuko Nagayoshi (Tohoku University), Hirofumi Taki (Hosei University), Hiroshi Kanbayashi (Tohoku Gakuin University), Hirohisa Takenoshita (Keio University) and Takashi Yoshida (Shizuoka University); Prizewinners of the 2019 FFJ/SASE Best Paper Award.

\section{DP 19-01 (May 2019)}

"A Study on New Mobility Services and Sustainable Urban Development", Ai Nishimura, 2017 FFJ/ Renault Fellow

\section{DP 18-06 (December 2018)}

"A Study of New Technologies of Personal Mobility and Robot Suit for the Elderly and Persons with Disabilities", Toshiaki Tanaka (University of Tokyo, Hokkaido University of Science), 2017 FFJ/Valeo Fellow

\section{DP 18-05 (November 2018)}

"Developments in Well-Being at Work in Japan: A Survey and a Comparison with France", Louise Baudrand (EHESS), César Castellvi (EHESS), Nao Kinoshita (EHESS), Adrienne Sala (Sciences Po Lyon) \& Sébastien Lechevalier (EHESS, Fondation France-Japon de l'EHESS)

\section{DP 18-04 (November 2018)}

"Understanding Al Driven Innovation by Linked Database of Scientific Articles and Patents", Kazuyuki Motohashi (University of Tokyo, NISTEP and RIETI, 2017 CEAFJP/Michelin Fellow)

\section{DP 18-03 (November 2018)}

"The Yen Exchange Rate and the Hollowing-out of the Japanese Industry", Ansgar Belke (University of Duisburg-Essen) \& Ulrich Volz (SOAS University of London, 2017 CEAFJP/Banque de France Fellow) 


\section{DP 18-02 (October 2018)}

"Cross-cultural (France and Japan) and Multidisciplinary Discussion on Artificial Intelligence and Robotics: Tendencies and Research Prospects", Naoko Abe (CEAFJP Research Fellow)

\section{DP 18-01 (July 2018)}

"Impact of Shareholder-Value Pursuit on Labor Policies at Japanese Joint-Stock Companies: Case of Nikkei Index 400", Kostiantyn Ovsiannikov (University of Tsukuba, Prizewinner of the 2018 FFJ/SASE Best Paper Award)

\section{DP 17-05 (November 2017)}

"Female Board of Directors and Organisational Diversity in Japan", Yukie Saito (CEAFJP Associate Researcher, University of Geneva, Institut de Recherches Sociologiques)

\section{DP 17-04 (August 2017)}

"Keiretsu Divergence in the Japanese Automotive Industry: Why Have Some, but Not All, Gone?", Akira Takeishi (Graduate School of Economics, Kyoto University; CEAFJP Visiting Researcher) et Yoshihisa Noro (Mitsubishi Research Institute, Inc.)

\section{DP 17-03 (June 2017)}

"Globalization and Support for Unemployment Spending in Asia: Do Asian Citizens Want to Embed Liberalism?", Sijeong Lim (University of Amsterdam) et Brian Burgoon (University of Amsterdam) ; Prizewinners of the SASE/FFJ Best Paper Award.

\section{DP 17-02 (April 2017)}

"Does 'Driving Range' Really Matter? The Hidden Cost of Internal Combustion Engine Vehicles and the Potentially New Value Proposition of Electric Vehicles: Two Cases from Countryside and Urban Side of Japan", Hidetada Higashi (2016 CEAFJP/ Valeo Fellow)

\section{DP 17-01 (March 2017)}

"How Can We Understand the Differences between France and Japan in the Growth of Shared Mobility Services? The Paradox of Trust and its Social Construction", Naoko Abe (2016 CEAFJP/Renault Fellow)

\section{DP 16-03 (September 2016)}

"Parameter Bias in an Estimated DSGE Model: Does Nonlinearity Matter?", Yasuo Hirose (Keio University) and Takeki Sunakawa (University of Tokyo)

\section{DP 16-02 (April 2016)}

"Financialization and Industrial Policies in Japan and Korea: Evolving Complementarities and Loss of Institutional Capabilities", Sébastien Lechevalier (EHESS), Pauline Debanes (EHESS), and Wonkyu Shin (Kyung Hee University)

\section{DP 16-01 (April 2016)}

"How Do Credit Hours Assure the Quality of Higher Education? Time-Based vs. CompetencyBased Debate", Ayaka Noda (National Institution for Academic Degrees and Quality Enhancement of Higher Education (NIAD-QE)

\section{DP 15-04 (December 2015)}

"Government Policy and the Evolution of Japan's Photovoltaic Industry, 1961-2014", Maki Umemura (Cardiff University, 2015 CEAFJP/Michelin Fellow)

\section{DP 15-03 (December 2015)}

"Japan's Financial Crisis and Lost Decades", Naohisa Hirakata (Bank of Japan), Nao Sudo (Bank of Japan), Ikuo Takei (Bank of Japan), Kozo Ueda (Waseda University, 2015 CEAFJP/Banque de France Fellow)

\section{DP 15-02 (May 2015)}

"Can Increased Public Expenditure Efficiency Contribute to the Consolidation of Public Finances in Japan?", Brieuc Monfort (CEAFJP Associate Researcher)

\section{DP 15-01 (May 2015)}

"Policy Regime Change Against Chronic Deflation? Policy Option under a Long-Term Liquidity Trap", Ippei Fujiwara (RIETI, Keio University, Australian National University), Yoshiyuki Nakazono (Yokohama City University), Kozo Ueda (Waseda University, 2014 CEAFJP/Banque de France Fellow) 